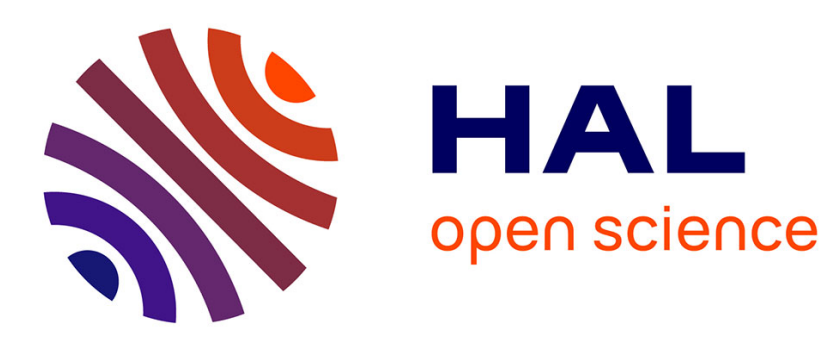

\title{
THE PATHOLOGY OF BONE MARROW FAILURE
}

Roos Leguit, Jan G van den Tweel

\section{To cite this version:}

Roos Leguit, Jan G van den Tweel. THE PATHOLOGY OF BONE MARROW FAILURE. Histopathology, 2010, 57 (5), pp.655. 10.1111/j.1365-2559.2010.03612.x . hal-00599534

\section{HAL Id: hal-00599534 https://hal.science/hal-00599534}

Submitted on 10 Jun 2011

HAL is a multi-disciplinary open access archive for the deposit and dissemination of scientific research documents, whether they are published or not. The documents may come from teaching and research institutions in France or abroad, or from public or private research centers.
L'archive ouverte pluridisciplinaire HAL, est destinée au dépôt et à la diffusion de documents scientifiques de niveau recherche, publiés ou non, émanant des établissements d'enseignement et de recherche français ou étrangers, des laboratoires publics ou privés. 


\section{Histopathology}

THE PATHOLOGY OF BONE MARROW FAILURE

\begin{tabular}{|c|c|}
\hline Journal: & Histopathology \\
\hline Manuscript ID: & HISTOP-02-10-0090 \\
\hline Manuscript Type: & Review \\
\hline $\begin{array}{r}\text { Date Submitted by the } \\
\text { Author: }\end{array}$ & 08-Feb-2010 \\
\hline Complete List of Authors: & $\begin{array}{l}\text { Leguit, Roos; UMC utrecht, Pathology } \\
\text { van den Tweel, Jan; UMC Utrecht, Pathology }\end{array}$ \\
\hline Keywords: & $\begin{array}{l}\text { bone marrow, histopathology, myelodysplastic syndromes, } \\
\text { inherited bone marrow failure syndromes, trephine biopsy }\end{array}$ \\
\hline
\end{tabular}

\section{scholarONE" \\ Manuscript Central}




\section{THE PATHOLOGY OF BONE MARROW FAILURE}

\section{Roos J Leguit \& Jan G van den Tweel}

University Medical Centre Utrecht

Department of Pathology H4.312

Heidelberglaan 100

3584 CX Utrecht

The Netherlands

Running title: Pathology of bone marrow failure

Keywords: bone marrow, histopathology, myelodysplastic syndromes, inherited bone marrow failure syndromes, trephine biopsy.

Address for correspondence:

R.J. Leguit:

rleguit2@umcutrecht.nl

Tel.: +31-88-7556565

Fax: $+31-30-2544855$ 


\begin{abstract}
:
An important indication for bone marrow investigation is the presence of bone marrow failure, which manifests itself as (pan)cytopenia. The causes of cytopenia are varied and differ considerable between childhood and adulthood. In the paediatric age group, inherited bone marrow failure syndromes are important causes of bone marrow failure but they play only a minor role in later life. This review gives a comprehensive overview of bone marrow failure disorders in children and adults. We classified the causes of bone marrow failure according to the main presenting haematological abnormality, i.e. anaemia, neutropenia, thrombocytopenia or pancytopenia. The following red cell disorders are discussed: red cell aplasia, sideroblastic anaemia, congenital dyserythropoietic anaemia, haemolytic anaemia, paroxysmal nocturnal haemoglobinuria, iron deficiency anaemia, anaemia of chronic disease and megaloblastic anaemia. The neutropenias occur in the context of Shwachman-Diamond syndrome, severe congenital neutropenia, cyclic neutropenia, immune-related neutropenia and non-immune neutropenia. In addition, the following causes of thrombocytopenia are discussed: congenital amegakaryocytic thrombocytopenia, thrombocytopenia with absent radii, immune-related thrombocytopenia and non-immune thrombocytopenia. Finally, we pay attention to the following pancytopenic disorders: Fanconi anaemia, dyskeratosis congenita, aplastic anaemia, myelodysplastic syndromes and HIV infection.
\end{abstract}




\section{Introduction}

An important indication for bone marrow investigation is the presence of bone marrow failure, which manifests itself as (pan)cytopenia. The causes of cytopenia are varied and differ considerable between childhood and adulthood as inherited bone marrow failure syndromes are important causes of bone marrow failure in the paediatric age group but play only a minor role in adulthood. The inherited bone marrow failure syndromes are frequently, but not always associated with physical abnormalities and sometimes the haematological abnormalities precede the onset of other abnormalities. Furthermore, some of these inherited syndromes may not be recognized until adulthood, ${ }^{1,2}$ and most of them are associated with an increased risk of developing myelodysplastic syndromes (MDS) or acute myeloid leukaemia (AML). Some syndromes, especially Fanconi anaemia and the Shwachman-Diamond syndrome, also have a tendency to progress to aplastic anaemia. The bone marrow in these inherited bone marrow failure syndromes is often hypocellular and may show some dysplastic changes making distinction from refractory cytopenia, a low-grade form of MDS, difficult or impossible at times.

In adults, common forms of anaemia are iron deficiency anaemia, megaloblastic anaemia, anaemia of chronic disease and haemolytic anaemia. Thrombocytopenia develops due to excessive use, excessive peripheral destruction or due to impaired production of platelets in the bone marrow. Neutropenia in adults is mainly autoimmune, drug related or associated with infections. In most cases of adult single cell cytopenia, a bone marrow trephine biopsy is not necessary for the diagnosis. However, in case of cytopenia of unknown origin or in case of pancytopenia, a bone marrow biopsy is often performed, amongst others to exclude or confirm the diagnosis of MDS. Since dysplasia of one or more cell lines can be seen not only in MDS but also in a wide variety of other situations as illustrated in this review, correlation with clinical parameters, the bone marrow aspirate, the peripheral blood smear and cytogenetics is essential in the assessment of bone marrow disorders.

This review gives a comprehensive overview of the histopathology of bone marrow failure in children and adults. The causes of bone marrow failure are classified according to the main presenting haematological abnormality (i.e. anaemia, neutropenia, thrombocytopenia or pancytopenia). HIV can cause significant dyshaematopoiesis simulating MDS and will be discussed under the heading of pancytopenia. Cytopenias associated with inherited 
immunodeficiency disorders or due to marrow infiltration by leukaemia and solid tumours will not be discussed in this review, neither will infections like kala azar, enteric fever, malaria, disseminated tuberculosis and leishmania, which are common causes of pancytopenia in non-Western countries., 3

\section{Anaemia}

Anaemia is a frequently occurring isolated disorder. In the majority of cases a bone marrow biopsy is redundant, since it does not add to the diagnosis, e.g. in patients with proven iron or Vitamin B12 deficiency. Nevertheless, there are situations in which a biopsy is performed in order to make a diagnosis or to exclude other pathologies.

\section{Pure Red Cell Aplasia}

Pure red cell aplasia (or erythroblastopenia) is a rare disease characterized by a moderate to severe normocytic anaemia, a profound reticulocytopenia and absence of erythroblasts in the bone marrow. It can be divided into three groups: a congential form called Diamond-Blackfan anaemia (DBA), an acquired acute self-limiting form predominantly seen in childhood called transient erythroblastopenia of childhood (TEC), and an acquired chronic form that occurs more frequently in adults. The inherited form, DBA, is associated with physical abnormalities like craniofacial anomalies, radial ray abnormalities, renal defects and cardiac defects in almost $50 \%$ of patients. ${ }^{2}$ This disorder typically presents in the first year of life, although it may be first recognized in adulthood. ${ }^{1,2}$ In addition to anaemia, the development of neutropenia and/or thrombocytopenia has been described during the course of the disease. ${ }^{5}$ The genes mutated in DBA that have been identified so far, encode ribosomal proteins. ${ }^{6,7}$ Less than 2 percent of DBA patients will develop haematopoietic or non-haematopoietic malignancies or MDS. ${ }^{2}$

Transient erythroblastopenia of childhood (TEC) occurs predominantly in young children with a mean age of 23 months. ${ }^{8}$ Neutropenia has been described in up to $65 \%$ of cases. ${ }^{9}$ The aetiology is still unknown, but infections by human herpes virus $6^{10}$ and parvovirus B19 11,12 have been demonstrated in some cases although these viruses could not be found in other studies. ${ }^{13}$ Genetic factors may also play a role, as several cases of TEC occurring in siblings 
and twins have been described. ${ }^{14,15}$ TEC is always self-limiting and spontaneous recovery usually occurs within 1 to 2 months.

The acquired chronic form of pure red cell aplasia can be primary or secondary to various underlying factors like infections, haematologic malignancies, solid tumours, collagen vascular diseases or drugs. ${ }^{16}$ Large granular lymphocyte leukaemia is the most common underlying haematologic malignancy. ${ }^{17}$ In up to $22 \%$ of patients with pure red cell aplasia, an associated thymoma is found.

The bone marrow in pure red cell aplasia is either normocellular or hypocellular and typically shows selective decrease or absence of red cell precursors beyond the proerythroblast stage (Figure 1). However, during the recovery phase of the disease, increased erythropoetic activity can be observed. ${ }^{18}$ The maturation of the granulocytic and megakaryocytic series is normal and iron stores are often increased. ${ }^{1,19}$ There is frequently an increase in haematogones (benign lymphoid precursors), which might lead to an erroneous diagnosis of acute lymphoblastic leukaemia. ${ }^{8,20}$ In parvovirus infections, enlarged proerythroblasts with intranuclear inclusions may be seen and the dyserythropoiesis might be so marked as to simulate congenital dyserythropoietic anaemia. ${ }^{21}$ Immunohistochemical stainings can be used to identify the parvovirus antigens.

\section{Sideroblastic anaemia}

Sideroblastic anaemia includes a heterogeneous group of rare conditions, characterized by the presence of ring sideroblasts in the bone marrow. Abnormal haem synthesis causes mitochondrial iron overload in erythroblasts. Several inherited forms have been described showing different modes of inheritance, a broad clinical spectrum and an initial clinical presentation ranging from foetal life to late childhood. The most frequent form is X-linked sideroblastic anaemia caused by mutations of delta-aminolevulinic acid synthase 2 (ALAS2), an enzyme involved in haem synthesis in erythroid precursors. Acquired forms of sideroblastic anaemia can be primary, as in refractory anaemia with ring sideroblasts (RARS), secondary due to the toxic effects of alcohol, lead and drugs, or due to copper deficiency. ${ }^{22-24}$ Once considered a morphological hallmark of sideroblastic anaemia, ring sideroblasts can also be seen in other conditions. 
The diagnosis of sideroblastic anaemia is usually made on the peripheral blood smear and the bone marrow aspirate, where dysmorphic erythrocytes, ring sideroblasts and erythroid hyperplasia are seen. Bone marrow trephine biopsies show some degree of erythroid hyperplasia with increased iron stores. Ring sideroblasts can be easily seen in plasticembedded material and smears. Decalcified paraffin-embedded biopsies might sometimes give false negative results. Bone marrow trephine biopsies are most useful in distinguishing sideroblastic anaemia from MDS, the latter showing also dysplastic changes in the granulocytic and megakaryocytic lineages.

\section{Congenital dyserythropoietic anaemia}

Congenital dyserythropoietic anaemia (CDA) comprises a group of rare inherited disorders of erythropoiesis usually characterized by a mild to moderate anaemia, ineffective erythropoiesis and frequently striking dyserythropoietic changes in the red cell precursors. The group of CDA was originally classified in three types (I,II, III), but variants have been reported and classified as type IV-VII. ${ }^{25}$ In CDA II, the most frequent form, there is typically a positive acidified serum test (Ham test), thereby mimicking paroxysmal nocturnal haemoglobinuria. The mode of inheritance can be autosomal recessive or autosomal dominant. CDA I in particular is associated with dysmorphic features which mainly affect the distal extremities. ${ }^{26}$ Thrombocytopenia has been described in patients with CDA II. ${ }^{27}$

The characteristic dyserythropoietic features of CDA can be best observed in the bone marrow aspirate, a bone marrow trephine biopsy usually does not add to the diagnosis. The bone marrow trephine will confirm the often marked dyserythropoiesis and erythroid hyperplasia. ${ }^{25,28}$ Megaloblastic changes are seen in most types, ${ }^{25,28}$ and iron stores are often increased. ${ }^{28} \mathrm{CDA}$ I is characterized by megaloblastic changes with internuclear chromatin bridges between erythroblasts. CDA II typically has large portions (10-40\%) of binucleated and multinucleated erythroblasts, shows increased karyorrhexis, and may contain pseudoGaucher cells. ${ }^{29}$ The most distinctive feature of CDA III is the high proportion of giant multinucleated erythroblasts with up to 12 nuclei. ${ }^{25}$ Although typical for CDA III, these giant multinucleated erythroblasts can also be seen in MDS and erythroleukaemia. Non-erythroid haematopoietic cell lineages are usually normal in CDA, but in patients with thrombocytopenia a severe reduction of megakaryocytes has been described ${ }^{27} \mathrm{CDA}$ must be differentiated from other inherited and acquired disorders showing dyserythropoiesis, such as thalassaemia, sideroblastic anaemia, vitamin B12 or folate deficiency, iron deficiency, excess 
alcohol intake, MDS, AML, paroxysmal nocturnal haemoglobinuria, aplastic anaemia, AIDS, infections like malaria and kala azar, or liver disease. ${ }^{26}$ As some cases of CDA may present rather late in life they can be misdiagnosed as MDS. The latter, however, will show dysplastic changes in other cell lineages as well.

\section{Haemolytic anaemia}

Haemolytic anaemia is caused by increased destruction of red cells and can be inherited or acquired. Inherited haemolytic anaemia is either due to red cell membrane defects like in hereditary spherocytosis, due to haemoglobin abnormalities as in thalassaemia and sickle cell anaemia, or due to metabolic disorders of the red cell, like in G6PD deficiency. In thalassaemia, there is additionally ineffective erythropoiesis.

Acquired haemolytic anaemia can be immune-related or non-immune. Haemolytic disease of the newborn (erythroblastosis foetalis) is the result of the immune destruction of foetal red cells by alloantibodies transmitted through the placenta from maternal blood. Evans syndrome is a childhood disorder caused by autoantibodies against red blood cells and platelets, resulting in haemolytic anaemia and thrombocytopenia. In paroxysmal nocturnal haemoglobinuria (PNH), haemolytic anaemia develops due to an acquired stem cell abnormality resulting in alterations in the cell membrane composition and is discussed separately below.

Regardless of the cause of haemolytic anaemia, the bone marrow shows hypercellularity with substantial erythroid hyperplasia, sometimes with a left shift and variable dyserythropoiesis. Iron stores are increased, sometimes extensively. In addition, autoimmune haemolytic anaemia often shows small lymphoid infiltrates. In thalassaemia major, the erythroid hyperplasia is extensive with complete replacement of the fat cells and marked dyserythropoiesis, sometimes with megaloblastic changes. ${ }^{30}$ Macrophages are often increased in number and can have the form of pseudo-Gaucher cells ${ }^{31,32}$ or sea-blue histiocytes. A variable degree of granulocytic and megakaryocytic hyperplasia has been described in thalassaemia, and increased karyorrhexis is indicative of the ineffective haematopoiesis. ${ }^{30}$ The dyserythropoiesis can be so marked that it can mimic CDA.

In sickle cell disease, sickle cells may be seen within bone marrow sinusoids during episodes of sickling. However, sickle cells can also be found in patients with the sickle cell trait.

During a sickle cell crisis, infarction of bone and bone marrow may be present, while fibrotic 
scars with areas of new bone formation and foamy macrophages are signs of previous infarctions.

\section{Paroxysmal nocturnal haemoglobinuria}

Paroxysmal nocturnal haemoglobinuria (PNH) is an uncommon acquired haematological disorder characterized by intravascular haemolysis, nocturnal haemoglobinuria, thrombotic events, serious infections, and bone marrow failure. It results from a non-malignant clonal expansion of one or more haematopoietic stem cells that have acquired mutations in an $\mathrm{X}$ linked gene, PIGA, causing affected cells and their progeny to be deficient in the complement regulator glycosylphosphatidylinositol anchored proteins (GPI-AP). This deficiency causes increased susceptibility of red cells to complement, resulting in intravascular haemolysis. ${ }^{33} \mathrm{In}$ addition to anaemia, neutropenia and thrombocytopenia are common features. ${ }^{34}$ The mean age of presentation is 33 years with a broad range (6-82 years). ${ }^{34}$ There is a close relationship between PNH and aplastic anaemia (AA). Thirty percent of PNH patients have a previous history of AA. ${ }^{34}$ On the other hand, $\mathrm{PNH}$ clones (often repeatedly recurring) are observed in a high percentage of patients with AA. ${ }^{35}$ Classic $\mathrm{PNH}$ requires features of intravascular haemolysis. Patients with AA and small to moderate PNH clones but without signs of haemolysis are often referred to as having an AA/PNH overlap syndrome.

Bone marrow cellularity in classical PNH ranges from normocellular to hypercellular with marked erythroid hyperplasia. Hypocellular bone marrow with relative red-cell hyperplasia is seen in cases of AA/PNH overlap syndrome. Some degree of dyserythropoiesis may be present and distinction from low grade MDS, especially in children, can often not be made on morphological grounds alone.

\section{Iron deficiency anaemia}

Iron deficiency anaemia develops due to shortages of iron stores and typically is microcytic and hypochromic. Thrombocytosis and, in severe iron deficiency, thrombocytopenia has been reported. ${ }^{36,37}$ Although this disease is usually acquired and can be attributed to chronic blood loss or inadequate dietary intake, an inherited autosomal recessive disorder has recently been described, causing an iron-refractory iron deficiency anaemia (IRIDA). ${ }^{38-40}$ IRIDA is unresponsive to oral iron therapy and is partially responsive to parenteral iron therapy. It is caused by mutations in the TMPRSS6 gene which encodes a transmembrane serine protease 
produced in the liver that controls the expression of hepcidin, a hormone regulating systemic iron. $^{38-40}$

The bone marrow in iron deficiency anaemia usually shows a mild to moderate erythroid hyperplasia with a predominance of intermediate normoblasts. However, when the anaemia becomes more chronic, erythropoiesis can be decreased. Dyserythropoiesis, correlated with the severity of iron deficiency, can be seen as nuclear irregularities, increased karyorrhexis and erythroblast multinuclearity. ${ }^{41}$ In case of additional thrombocytopenia, megakaryocytes are reported to be decreased, adequate or increased. ${ }^{36}$ The bone marrow reticulum cells are characteristically depleted of iron. In case of IRIDA, however, the bone marrow may show detectable iron after intravenous iron therapy, while serum iron concentrations remain low. ${ }^{39}$ Sometimes, decalcification needed for paraffin-embedded trephine biopsies may leach out some or all of the iron, so that a positive iron staining can rule out iron deficiency anaemia, but a diagnosis of iron deficiency cannot always be made on decalcified specimens.

\section{Anaemia of chronic disease / anaemia of chronic inflammation}

Anaemia of chronic disease (ACD) is a common cause of anaemia in adults and is primarily found in patients with diseases causing immune activation like chronic infections, autoimmune disorders, malignancies, chronic organ rejection and chronic kidney diseases. ${ }^{42}$ In autoimmune diseases, ACD is the main mechanism of anaemia, although this can also be caused by other mechanisms such as iron deficiency or drug effects. ${ }^{43}$ In addition, autoimmune disorders can be associated with pure red cell aplasia, ${ }^{44,45}$ aplastic anaemia, ${ }^{46}$ haemophagocytic syndrome ${ }^{47}$ and autoimmune myelofibrosis. ${ }^{48}$ Although anaemia in chronic kidney diseases can be the result of inflammatory changes and ACD, it could also merely be due to a poor production of erythropoietin.

In ACD, T-cells and monocytes are activated resulting in the production of cytokines and eventually in disturbances in iron homeostasis, impaired proliferation of erythroid progenitor cells and an inadequate erythropoietin response. ${ }^{42}$ Hepcidin, the liver hormone regulating iron metabolism, plays an important role in ACD. ${ }^{42,49-51}$ The anaemia is typically normocytic and normochromic.

The bone marrow in anaemia of chronic disease can be hypocellular, normocellular or hypercellular. ${ }^{52,53}$ Most often there is erythroid hypoplasia, though the erythropoiesis can be normal or even increased. ${ }^{52-54}$ The myeloid and megakaryocytic series are frequently 
increased, but can be normal or decreased. ${ }^{52,53}$ Dysplastic changes in all cell lineages are present in the vast majority of cases. ${ }^{52-55}$ Although some authors claim that there is no correlation between myelodysplastic changes in the bone marrow and disease activity, ${ }^{53}$ others do and even describe disappearance of the dysplasia with remission of the autoimmune disorder. ${ }^{55}$ Iron stores are normal or increased unless a coexisting iron deficiency anaemia is present. Other bone marrow findings include architectural disturbances with paratrabecular localization of erythroid and megakaryocytic precursors, increase in reticulin fibres and occasionally collagen fibrosis with osteosclerosis, necrosis, dilatation of sinuses and the presence of lymphoid aggregates. ${ }^{52}$ Furthermore, an increase in polytypic plasma cells of up to $33 \%$ has been described in autoimmune disorders. ${ }^{54,56,57}$

\section{Megaloblastic anaemia}

Megaloblastic anaemia comprises a heterogeneous group of disorders characterized by macrocytaemia in the blood smear occurring due to impaired DNA synthesis. The mildest form shows only macrocytosis without anaemia. Severe cases may also show leucopenia and/or thrombocytopenia, since DNA synthesis is affected in all haematopoietic cell lineages. The most common cause of megaloblastic anaemia is vitamin B12 or folate deficiency. Vitamin B12- and folate-independent causes of megaloblastic anaemia are inherited or acquired abnormalities of nucleic acid synthesis (mostly due to drugs), complex mechanisms or unknown mechanisms as in MDS, AML and CDA. ${ }^{58}$ Pernicious anaemia is a specific form of megaloblastic anaemia due to vitamin B12 deficiency in the setting of autoimmune atrophic gastritis.

In megaloblastic anaemia due to vitamin B12 or folate deficiency, the bone marrow is usually markedly hypercellular with striking erythroid hyperplasia and numerous megaloblasts, although the $\mathrm{M} / \mathrm{E}$ ratio may be increased. The picture can sometimes simulate acute myeloid leukaemia. In non-anaemic cases, erythropoiesis may be normoblastic or only mildly megaloblastic. ${ }^{58}$ Granulocytic precursors can also be increased and often show nuclear/cytoplasmic asynchrony in the form of giant metamyelocytes and giant bands. There can be a reduction of megakaryocytes, which may be abnormally large and hyperlobulated even with bizarre multilobated nuclei. Iron stores may vary between increased and decreased. After start of therapy, conversion to normoblastic haematopoiesis begins within 12 hours and is usually complete within 2-3 days. 


\section{Neutropenia}

Severe neutropenia is defined as an absolute blood neutrophil count $<500 / \mu \mathrm{L}$. The acute form is most often caused by drugs or acute viral infections, ${ }^{59}$ usually lasts only a few days or weeks and is generally not biopsied. The chronic form can be due to a variety of underlying disorders that may be either congenital or acquired. ${ }^{60}$

\section{Shwachman-Diamond syndrome}

Shwachman-Diamond syndrome (SDS) is a rare autosomal recessive inherited disorder characterized by insufficiency of the exocrine pancreas (replacement by fat), metaphyseal chondrodysplasia, growth retardation and other physical abnormalities. Neutropenia, chronic or intermittent, is the most important haematological abnormality and is observed in $88-100 \%$ of patients, but anaemia and/or thrombocytopenia also frequently occur. ${ }^{61-65}$ Recurrent infections, sometimes fatal, are common. Approximately $90 \%$ of patients meeting the clinical criteria of SDS have mutations in the SBDS gene on chromosome $7 .^{66}$ The disease has a propensity to develop into aplastic anaemia, MDS or AML, although clonal chromosome anomalies may persist for a long time without evolving to MDS or AML, and may even regress. ${ }^{62,67}$ Although the marrow dysplasia and cytogenetic abnormalities are nearly equally distributed among the sexes, progression to AML occurs predominantly in males. ${ }^{63,67}$

The bone marrow cellularity in SDS is most often decreased, but may be normal or even increased. ${ }^{63,65}$ Maturation arrest or absence or myeloid precursors is seen in only a minority of patients (Figure 2). ${ }^{61,63,65}$ Normal bone marrow aspirates have been described, even during episodes of neutropenia, but this may be due to patchy distribution of the hypoplasia. ${ }^{61,63}$ Mild dysplastic changes in granulopoiesis, erythropoiesis or megakaryopoiesis as assessed on aspirates, are common and can be transient. ${ }^{62,63,65}$ These dysplastic changes are considered to be part of the syndrome and not indicative of MDS. ${ }^{62}$ When pancytopenia develops, marrow changes consistent with aplastic anaemia are seen. Furthermore, bone abnormalities consistent with low turnover osteoporosis frequently occur. There often is a marked reduction in trabecular bone volume, in the amount of osteoid (with normal mineralization) and in numbers of osteoblasts and osteoclasts. ${ }^{68}$ The osteoporosis is thought to be an integral feature of SDS that might be directly related to the bone marrow dysfunction and neutropenia. ${ }^{68}$ 


\section{Severe congenital neutropenia and Kostmann syndrome}

Severe congenital neutropenia ( $\mathrm{SCN})$ is a form of chronic neutropenia. It was originally described in 1956 by Kostmann as an autosomal recessive inherited marrow failure syndrome involving only the neutrophilic lineage. ${ }^{69}$ Subsequently it was found to consist of a heterogeneous group of disorders with either an autosomal dominant or autosomal recessive pattern of inheritance, or sometimes occurring sporadically. Several molecular defects have been identified in SCN. The majority of patients have an autosomal dominant trait mainly due to mutations in ELA2, the gene encoding neutrophil elastase. ${ }^{70,71}$ The autosomal recessive form (Kostmann syndrome) accounts for about $30 \%$ of cases and is mostly due to mutations in the $H A X 1$ gene. $^{72}$ In others, the underlying molecular cause is still unknown. SCN usually becomes symptomatic within the first 6 months of life, presenting with severe pyogenic infections. The total white cell count may be close to normal due to increased numbers of eosinophils and monocytes. ${ }^{71,73}$ There can be a mild anaemia and thrombocytosis ${ }^{73}$ and there is an increased risk of transformation to MDS, ${ }^{74}$ or AML. ${ }^{75}$ Rosenberg et al studied 374 patients with SCN and found that the cumulative incidence for MDS/AML was $21 \%$ after 10 years of G-CSF therapy and $36 \%$ after 12 years. ${ }^{75}$

In SCN, bone marrow cellularity is normal or slightly decreased, with a characteristic absence of fully developed granulocytes which occurs due to a maturation arrest at the promyelocyte or myelocyte stage (Figure 3). ${ }^{71,73,76}$ During infections however, there can be a transient increase of mature neutrophils whereas maturation of other haematopoietic lineages is normal. Marrow monocytosis and eosinophilia are common. ${ }^{73}$ In cases where neutropenia results from infections, drugs, allo- or autoimmunity, metabolic disorders or immunodeficiency syndromes, the bone marrow shows complete maturation of the granulocytic series, or blockage only at the band stage.

\section{Cyclic neutropenia}

Cyclic neutropenia, also a form of chronic neutropenia, is characterized by regular periods in which the number of granulocytes fluctuates from normal to (severely) neutropenic, lasting for between 19 and more than 21 days. $^{77}$ In addition, there is an inverse oscillation of the platelets, often of the monocytes and eosinophils and occasionally of the reticulocytes, which all oscillate from normal to high levels. ${ }^{77}$ Cyclic neutropenia occurs sporadically or as a result of autosomal dominant inheritance. As in severe congenital neutropenia, ELA2 mutations are 
the most common cause for both sporadic and autosomal dominant cyclic neutropenia. ${ }^{71,78}$ There is insufficient evidence for an increased risk of MDS and AML in cyclic neutropenia. ${ }^{79-}$ 81

In cyclic neutropenia, maturation arrest or absence of granulocyte precursors in the otherwise unremarkable bone marrow precedes peripheral blood neutropenia, and is followed by a return to normal maturation before the improvement of peripheral blood counts. ${ }^{80,82,83}$

\section{Immune-related neutropenia}

Immune-related neutropenia can be divided in autoimmune, alloimmune and drug-related neutropenia. Autoimmune neutropenia can occur as an isolated phenomenon, or as one of the manifestations of an autoimmune disease such as systemic lupus erythematosus. Alloimmune neutropenia can occur after allogeneic stem cell transplantation. Although drug associated neutropenia can be due to antineutrophil antibodies, the main mechanism of most druginduced neutropenias is non-immune.

The bone marrow in autoimmune neutropenia usually shows normal or hyperplastic granulopoiesis with a reduced proportion of mature neutrophils, sometimes with a maturation arrest at the promyelocyte stage. ${ }^{84}$ Occasionally, lipidladen macrophages or sea-blue histiocytes are seen. ${ }^{85}$ In autoimmune neutropenia of infancy, phagocytosis of neutrophils by bone marrow macrophages has been described. ${ }^{86}$ In drug-induced autoimmune neutropenia, the marrow can be normo- or hypocellular with marked hypoplasia and left-shifting of the myeloid series with unremarkable erythropoiesis and megakaryopoiesis, sometimes in the presence of lymphohistiocytic aggregates, small noncaseating granulomas and lipogranulomas. ${ }^{87}$

\section{Non-immune neutropenia}

Chronic neutropenia not related to an immune phenomenon can be idiopathic or associated with infections (notably typhoid fever), metabolic disorders, immunodeficiency and drugs. In the chronic idiopathic form, impaired granulopoiesis might be due to overproduction of cytokines by immune cells within the bone marrow microenvironment, that may exert an inhibitory effect on myelopoiesis by inducing Fas-mediated apoptosis in the granulocyte progenitors. ${ }^{88}$ It typically has a low incidence of infection and usually has a benign outcome. 
The bone marrow features in chronic idiopathic neutropenia are well described by Papadaki et $a l .{ }^{89}$ The bone marrow trephine biopsy is usually normocellular, but can be hypocellular or hypercellular. In nearly half the cases, the granulocytic series shows left shifting, which is most profound in patients with severe neutropenia. Granulopoiesis is hyperplastic in a minority of cases. Erythropoiesis can be slightly hyperplastic with occasional megaloblastic features. Megakaryopoiesis is usually normal, but can sporadically be increased or contain micromegakaryocytes. An increased proportion of plasma cells is seen in half of cases and is inversely correlated to the number of circulating neutrophils. Non-paratrabecular lymphoid aggregates without germinal centres are frequently found and there can be an increase in the numbers of dispersed B-lymphocytes. Eosinophils and histiocytes as well as reticulin fibers can be slightly increased.

\section{Thrombocytopenia}

Inherited forms of thrombocytopenia are rare; two of them will be discussed. Acquired forms of thrombocytopenia can be seen in both children and adults, and often occur in combination with other cytopenias such as aplastic anaemia or MDS. Several acquired forms of isolated thrombocytopenia are discussed below.

\section{Congenital amegakaryocytic thrombocytopenia}

Congenital amegakaryocytic thrombocytopenia (CAMT) is characterized by severe thrombocytopenia due to a lack of megakaryocytes. It presents at birth with haemorrhages of the skin or gastrointestinal tract mucosa without the physical anomalies typical of other inherited bone marrow failure syndromes. In most patients with CAMT, mutations in the $c$ $m p l$ gene coding for the thrombopoietin (TPO) receptor are present. ${ }^{90}$ A very high proportion of patients subsequently develop multilineage bone marrow failure/aplastic anaemia in the first or second decade of life, which also seems to be the result of the $c$-mpl mutations. ${ }^{91}$

At the time of diagnosis, the bone marrow trephine usually shows normal cellularity with absent or low numbers of megakaryocytes but unremarkable erythropoiesis and granulopoiesis (Figure 4). ${ }^{91}$ When present, the megakaryocytes are usually small and immature. ${ }^{92}$ Although a few CAMT patients have been described with normal numbers of megakaryocytes in the initial bone marrow samples, serial bone marrow samples in these 
patients show progression to amegakaryocytosis. ${ }^{93}$ When aplastic anaemia develops, it is morphologically indistinguishable from aplastic anaemia due to other causes.

\section{Thrombocytopenia with absent radii}

Thrombocytopenia with absent radii (TAR) is a rare inherited disorder that usually has an autosomal recessive mode of inheritance. It is characterized by a usually severe thrombocytopenia at birth and bilaterally absent radii. In contrast to Fanconi anaemia, thumbs are present. Skeletal abnormalities of the lower extremities as well as cardiac, renal and facial anomalies can be present. About half of patients have cow's milk intolerance. Other characteristic findings are periodic leukaemoid reactions and eosinophilia. ${ }^{94}$ Platelet numbers increase with age and can reach near-normal levels in adulthood. Anaemia may develop secondary to extensive bleeding. The genetic basis of this syndrome is still unclear. ${ }^{95}$

The bone marrow in TAR is normo- or hypercellular with absent or decreased megakaryocytes, which, if present, are small, hypolobulated and immature. ${ }^{96}$ When platelet counts increase, the number of megakaryocytes also increases and more mature forms are seen. Erythropoiesis is normal or hyperplastic secondary to the bleeding episodes, but can occasionally be decreased. ${ }^{96}$ Granulopoiesis is normal or increased and can be left shifted, especially during a leukaemoid reaction. Eosinophilia is common.

\section{Immune-related thrombocytopenia}

Immune thrombocytopenic purpura (ITP) is usually the result of autoantibodies causing increased removal of platelets by the spleen and liver, although ineffective platelet production also seems to play a role. ${ }^{97}$ ITP is classified as primary (idiopathic) versus secondary or as acute (usually in childhood) versus chronic (usually in adult women). ${ }^{97}$ Secondary ITP can be associated with other autoimmune diseases, lymphoproliferative disorders, viral infections and drugs.

Alloantibodies can cause thrombocytopenia after blood transfusion and neonatally when maternal antibodies are transmitted through the placenta.

In ITP, the bone marrow is normocellular with increased or normal numbers of megakaryocytes and unremarkable erythropoiesis and granulopoiesis. ${ }^{98,99}$ Rarely, 
megakaryocytes are decreased. ${ }^{98}$ Immature megakaryocytes with hypolobated nuclei are typical for ITP, although dysplastic megakaryocytes, naked megakaryocyte nuclei and, to a lesser degree, micromegakaryoctyes are also frequently found in ITP bone marrow aspirates. ${ }^{99}$ Secondary ITP may in addition show features of the associated disorder. When thrombocytopenia is due to direct megakaryocytic damage by allo- or drug-related antibodies, their number is usually reduced. TPO receptor agonists used in the treatment in ITP may induce reversible and dose-dependent bone marrow changes such as megakaryocyte hyperplasia and increased reticulin fibrosis. ${ }^{100}$

\section{Non-immune thrombocytopenia}

Non-immune thrombocytopenia can be due to impaired production of platelets in the bone marrow. Besides the above mentioned inherited amegakaryocytic syndromes, other (very rare) syndromes with congenital thrombocytopenia are known. An acquired syndrome called amegakaryocytic thrombocytic purpura (ATP) and its cyclic variant have been described in adults, being rare disorders characterized by severe thrombocytopenia with absence or marked reduction of megakaryocytes in the bone marrow. ${ }^{101,102}$ The aetiology seems to be multifactorial. ${ }^{101,102}$ Ineffective production of platelets is also the cause of thrombocytopenia in MDS, which is a clonal haematopoietic stem cell disorder.

Non-immune thrombocytopenia can furthermore be the result of increased utilization or destruction of platelets outside the bone marrow as seen in thrombocytic thrombocytopenic purpura (TTP), diffuse intravascular coagulation (DIC), haemolytic uremic syndrome (HUS) and certain infections.

In the amegakaryocytic thrombocytopenia syndromes, megakaryocytes are absent or markedly reduced with only small, immature forms. Very few abnormalities are present in the other haematopoietic cell lineages. In cyclic ATP, megakaryocytes are markedly reduced during platelet nadirs and atypical micromegakaryocytes can be seen. ${ }^{102}$ When platelet counts are increasing, the number of megakaryocytes becomes normal or increased and their morphology turns to normal. ${ }^{102}$ In MDS, megakaryocytes are dysplastic and dysplasia can be seen in other lineages too. When thrombocytopenia has developed acutely due to increased utilization or destruction of platelets, the bone marrow is morphologically normal. With time, however, there will be an in increase in the number of megakaryocytes together with a reduction in their average size. 


\section{Pancytopenia}

Pancytopenia can result from a wide variety disorders such as aplastic anaemia, MDS, acute leukemia, infections (most often HIV), familial haemophagocytic syndrome, severe folate or Vit.B12 deficiency, autoimmune disorders such as systemic lupus erythematosus, PNH, inherited bone marrow failure syndromes, hypersplenism or drugs. Some of these disorders more often present as a single cell cytopenia and have already been discussed, others are discussed below.

\section{Fanconi anaemia}

Fanconi anaemia (FA) is an autosomal recessive or, rarely, X-linked recessive bone marrow failure syndrome with characteristically an abnormal high frequency of spontaneous chromosomal breakages and hypersensitivity to DNA cross-linking agents such as diepoxybutane and mitomycin-C. FA shows considerable genetic heterogeneity, with 13 subtypes currently recognized. ${ }^{103-105}$ It is associated with a wide range of congenital abnormalities including generalized hyperpigmentation of the skin, microphthalmia, radial ray anomalies, genitourinary abnormalities and short stature. However, in about $30 \%$ of FA patients no physical abnormalities are found. ${ }^{106}$ Haematological abnormalities generally develop during the first decade, usually starting with thrombocytopenia and/or anaemia, eventually progressing to pancytopenia in $>90 \%$ of patients. ${ }^{105}$ There is a strikingly increased risk of MDS, AML and solid tumours, particularly squamous cell carcinomas of the head and neck, anogenital regions and skin. ${ }^{107}$ The development of MDS is highly associated with the presence of clonal chromosomal abnormalities, mostly involving chromosomes 1,3 and $7 .{ }^{108}$ The first presentation of FA may be in adulthood with marrow failure or a malignancy. ${ }^{109}$

In early stages, the bone marrow of FA patients might still be normocellular but with disease progression, it becomes increasingly hypocellular and eventually a histological picture indistinguishable from other forms of aplastic anaemia will ensue. Megakaryocytes are often decreased in number. The erythroid lineage usually shows hyperplasia with erythroblastic islands, megaloblastic changes and dysplasia. ${ }^{108,110,111}$ As dysplasia limited to the erythroid lineage is frequently found in FA, one must be very hesitant to regard these findings as MDS (Figure 5). Chioc et al. described the morphological and cytogenetic characteristics of FArelated MDS. ${ }^{108}$ An increase in blasts and the presence of dysgranulopoiesis are the most 
reliable criteria for diagnosing FA-related MDS, and are highly correlated to the presence of clonal abnormalities, followed by dysmegakaryopoiesis. ${ }^{108}$

\section{Dyskeratosis congenita}

Dyskeratosis congenita (DC) is typically characterized by the mucocutaneous triad of nail dystrophy, mucosal leucoplakia and abnormal skin pigmentations, although a variety of other abnormalities have been reported. The classical features usually appear during childhood. ${ }^{112}$ The pattern of inheritance may be X-linked recessive, autosomal dominant or autosomal recessive. The mutations that have been identified thus far interfere with telomerase activity, although the genetic basis of disease is still unknown in the majority of patients. ${ }^{113,114}$ DC has an increased risk of MDS and acute leukaemia as well as of solid tumours, especially squamous cell carcinomas. Most patients (>90\%) progress to aplastic anaemia with bone marrow failure being the major cause of mortality. ${ }^{112}$ The onset of cytopenia can precede the appearance of the characteristic mucocutaneous triad.

The bone marrow findings in DC range from normal to variable stages of aplasia depending on the stage of the disease and eventually will be indistinguishable from aplastic anaemia due to other causes.

\section{Aplastic anaemia}

Aplastic anaemia (AA) is characterized by pancytopenia and an acellular or markedly hypocellular bone marrow. AA can be idiopathic $(\sim 70 \%)$, inherited $(\sim 15-20 \%)$ or secondary to radiation, drugs, viruses or immune disorders $(\sim 10-15 \%) .{ }^{105}$ Idiopathic and secondary AA are usually immune mediated by autoreactive lymphocytes mediating destruction of haematopoietic stem cells. ${ }^{115}$ The clinical course of AA is highly variable with some patients having only mild symptoms, needing little or no therapy, and others presenting with lifethreatening pancytopenias. ${ }^{115}$ Patients with AA are at risk for the development of clonal disorders, e.g. PNH clones. ${ }^{35,116}$ In addition, the development of MDS $^{117-119}$ and AML is related to emerging clonal chromosomal abnormalities, mostly monosomy 7 . It is important to identify patients with AA in the setting of one of the inherited bone marrow failure syndromes as these rarely respond to immunosuppressive therapy. Since the histopathology of idiopathic, inherited and secondary AA is similar, the distinction can only be made by ancillary tests. Furthermore, it is important to differentiate AA from hypocellular MDS and hypocellular AML. 
A trephine biopsy is essential for diagnosing AA and whatever the underlying cause, bone marrow morphology is similar. There is a marked reduction in haematopoietic cells with replacement by fat cells and a variable inflammatory infiltrate of plasma cells, mast cells, interspersed or aggregated lymphocytes, macrophages and sometimes eosinophils (Figure 6). This reactive infiltrate might be so extensive that at first glance the marrow may even seem hypercellular. In addition, there may be oedema and/or haemorrhages, ${ }^{120,121}$ necrosis or cellular debris. Macrophage iron is often increased; the amount of reticulin is normal or only slightly increased. Some cases may contain so-called hot spots: hypercellular areas consisting mainly of erythroid precursors which are often left-shifted and synchronized at the same stage of development. ${ }^{121}$ In adults, clusters of more than 20 erythroid cells and the presence of leftshifted and/or synchronized erythropoiesis in an otherwise empty marrow are considered part of AA. In children however, these findings should be regarded as evidence for refractory cytopenia of childhood, a low-grade form of paediatric MDS, according to the WHO classification $2008 .{ }^{122}$ In addition, aplasia and dyserythropoiesis are frequently found in Fanconi anaemia so this disorder should always be excluded by ancillary chromosomal breakage tests before diagnosing AA or MDS in young persons. Furthermore, the presence of dyserythropoiesis in an aplastic marrow should also raise the question of $\mathrm{PNH}$-associated AA in both children and adults.

It is always important to differentiate AA from hypocellular MDS (h-MDS). In AA, cell atypia is found only in erythroblasts and not in other cell lineages. ${ }^{123}$ While megakaryocytes are absent or reduced in numbers but otherwise normal in $\mathrm{AA},{ }^{121}$ they are present and atypical in the majority of cases of h-MDS. ${ }^{123}$ The presence of reticulin fibrosis further favours hMDS over AA. ${ }^{124}$ The amount of CD34 positive blasts is often low in AA, whereas it is normal or increased in h-MDS. ${ }^{125,126}$ In hypocellular AML, another important differential diagnosis of AA, the amount of blasts is per definition increased ( $\geq 20 \%$ in adults and $\geq 30 \%$ in children). Their identification by immunostains is therefore crucial.

Finally, it should be kept in mind that subcortical bone and sites other than central axial bone marrow normally contain little haematopoiesis in adult patients, so that trephine biopsy specimens taken from these areas are not suitable for diagnosing AA.

\section{Myelodysplastic syndromes}

Myelodysplastic syndromes (MDS) are a heterogeneous group of clonal haematopoietic stem cell disorders characterized by ineffective haematopoiesis resulting in peripheral cytopenia, 
and a propensity to progress to AML. MDS mainly occur in the elderly, but occasionally can be seen in childhood as well. ${ }^{127,128}$ In adults, low-grade MDS usually present with anaemia whereas in childhood they more often present with thrombocytopenia or leukopenia. ${ }^{129}$ Two thirds of cases of paediatric MDS are considered primary, whereas one third of cases has an association with an inherited/constitutional disorder or follows chemotherapy. The most recent WHO classification recognizes several subgroups, mainly based on morphology, blast count and cytogenetic abnormalities. ${ }^{130}$ The threshold for diagnosing AML is an increase in myeloblast in peripheral blood or bone marrow of $\geq 20 \%$ in adults and of $\geq 30 \%$ in children. However, MDS secondary to chemotherapy or radiation therapy should be classified together with therapy-related AML as 'therapy-related myeloid neoplasm' regardless the blast count. Furthermore, MDS associated with Down syndrome, which accounts for 20-25\% of cases of MDS occurring in childhood, ${ }^{131}$ is considered to be a unique biological entity and is classified together with AML as 'Down syndrome-related myeloid leukaemia' irrespective of the blast count.

The bone marrow of patients with MDS usually is hypercellular but hypocellularity can be seen, especially in children. ${ }^{132}$ Dyshaematopoiesis is the hallmark of the disease and the bone marrow architecture is usually disturbed (Figure 7). There is often erythroid hyperplasia and dyserythropoies is manifested by left-shifting, synchronization of the erythroid precursors within the erythroid islands, nuclear abnormalities and sometimes presence of megaloblasts. Dysgranulopoiesis is characterized by decreased maturation of the myeloid precursors and clusters of immature myeloid precursors abnormally located in the centre of the bone marrow fields (so-called ALIPs) which are typically seen in high-grade MDS. In trephine bone marrow biopsies, dysplastic features are most prominent in the megakaryocytes, which typically show hypolobulation, wide separation of the nuclear lobes, rounded nuclei and micromegakaryocytes. Iron stores are increased due to ineffective haematopoiesis or transfusions and significant fibrosis can be seen in approximately $10 \%$ of cases. Other common findings include the presence of oedema, increased number of microvessels, plasmacytosis, increased mast cells, macrophages with increased cellular debris, lymphocytosis and lymphoid follicels. ${ }^{133}$ The dysplastic features of hypocellular MDS are similar to the normo- and hypercellular forms. ${ }^{133}$ Distinction of hypocellular MDS form AA is important and is discussed under AA (see above). 


\section{HIV}

Patients with HIV infection can suffer from various cytopenias and late in the course of the disease, pancytopenia with marked lymphopenia may ensue. A bone marrow biopsy may be performed in search of infection, for staging of malignant lymphoma or to rule out MDS. Since dysplastic changes are a feature of HIV infection itself, or can be induced by antiretroviral therapy distinction from MDS can be challenging. Furthermore, superimposed infections can complicate the picture.

The bone marrow in patients with HIV can be either hypercellular, normocellular or hypocellular. ${ }^{134}$ The normal bone marrow architecture is often disturbed and dysplastic changes are almost always present which can be similar to those of MDS. However, dyserythropoiesis is usually less severe in HIV than in MDS and occurs mainly in patients treated with HAART therapy with megaloblastic changes being particularly associated with AZT therapy. ${ }^{135,136}$ In contrast to MDS, in which erythropoiesis is usually hyperplastic, the myeloid/erythroid ratio in HIV is usually normal and initially there may even be neutrophilic and megakaryocytic hyperplasia in HIV. ${ }^{136}$ An increase in blasts can be seen in MDS, but never in HIV. In addition, bone marrow trephine biopsies in HIV patients often show eosinophilia, lymphohistiocytic infiltrates and reactive plasmacytosis. ${ }^{137}$ Granulomas are encountered in approximately $15 \%$ of bone marrow trephines and might by merely due to the HIV infection but a thorough search for other infections is required. HIV associated stromal changes include edema, gelatinous transformation and increased reticulin fibers. ${ }^{136,137}$ Dense collagen fibrosis, however, is not a feature of HIV. ${ }^{136}$ In all instances one should carefully search for opportunistic infections, especially mycobacterial, fungal and protozoal infections. Lastly, there can be bone marrow involvement by lymphomas, Kaposi sarcoma and Castleman disease, resulting in bone marrow failure.

\section{Concluding remarks:}

Dyshaematopoiesis is the hallmark of MDS, but as illustrates in this review, dysplasia of one or more cell lines can be seen in a wide variety of other situations such as in inherited bone marrow failure syndromes, PNH, infections such as HIV and parvovirus B19, drugs and autoimmune diseases. Therefore, correlation with clinical parameters, the bone marrow aspirate, the peripheral blood smear and cytogenetics is essential in the assessment of bone marrow disorders. 


\section{Reference List}

1. Balaban EP, Buchanan GR, Graham M, Frenkel EP. Diamond-Blackfan syndrome in adult patients. Am. J. Med. 1985 Mar;78(3):533-538.

2. Lipton JM, Atsidaftos E, Zyskind I, Vlachos A. Improving clinical care and elucidating the pathophysiology of Diamond Blackfan anemia: an update from the Diamond Blackfan Anemia Registry. Pediatr. Blood Cancer 2006 May 1;46(5):558564.

3. Gupta V, Tripathi S, Tilak V, Bhatia BD. A study of clinico-haematological profiles of pancytopenia in children. Trop. Doct. 2008 Oct;38(4):241-243.

4. Memon S, Shaikh S, Nizamani MA. Etiological spectrum of pancytopenia based on bone marrow examination in children. J. Coll. Physicians Surg. Pak. 2008 Mar;18(3):163-167.

5. Giri N, Kang E, Tisdale JF, et al. Clinical and laboratory evidence for a trilineage haematopoietic defect in patients with refractory Diamond-Blackfan anaemia. Br. J. Haematol. 2000 Jan;108(1):167-175.

6. Ellis SR, Lipton JM. Diamond Blackfan anemia: a disorder of red blood cell development. Curr. Top. Dev. Biol. 2008;82:217-241.

7. Flygare J, Karlsson S. Diamond-Blackfan anemia: erythropoiesis lost in translation. Blood 2007 Apr 15;109(8):3152-3154.

8. Gerrits GP, van Oostrom CG, de Vaan GA, Bakkeren JA. Transient erythroblastopenia of childhood. A review of 22 cases. Eur. J. Pediatr. 1984 Sep;142(4):266-270.

9. Cherrick I, Karayalcin G, Lanzkowsky P. Transient erythroblastopenia of childhood. Prospective study of fifty patients. Am. J. Pediatr. Hematol. Oncol. 1994 Nov;16(4):320-324.

10. Penchansky L, Jordan JA. Transient erythroblastopenia of childhood associated with human herpesvirus type 6, variant B. Am. J. Clin. Pathol. 1997 Aug;108(2):127-132.

11. Prassouli A, Papadakis V, Tsakris A, et al. Classic transient erythroblastopenia of childhood with human parvovirus B19 genome detection in the blood and bone marrow. J. Pediatr. Hematol. Oncol. 2005 Jun;27(6):333-336.

12. Geetha D, Zachary JB, Baldado HM, Kronz JD, Kraus ES. Pure red cell aplasia caused by Parvovirus B19 infection in solid organ transplant recipients: a case report and review of literature. Clin. Transplant. 2000 Dec;14(6):586-591.

13. Skeppner G, Kreuger A, Elinder G. Transient erythroblastopenia of childhood: prospective study of 10 patients with special reference to viral infections. J. Pediatr. Hematol. Oncol. 2002 May;24(4):294-298.

14. Shaw J, Meeder R. Transient erythroblastopenia of childhood in siblings: case report and review of the literature. J. Pediatr. Hematol. Oncol. 2007 Sep;29(9):659-660. 
15. Skeppner G, Forestier E, Henter JI, Wranne L. Transient red cell aplasia in siblings: a common environmental or a common hereditary factor? Acta Paediatr. 1998 Jan;87(1):43-47.

16. Djaldetti M, Blay A, Bergman M, Salman H, Bessler H. Pure red cell aplasia--a rare disease with multiple causes. Biomed. Pharmacother. 2003 Oct;57(8):326-332.

17. Sawada K, Hirokawa M, Fujishima N, et al. Long-term outcome of patients with acquired primary idiopathic pure red cell aplasia receiving cyclosporine A. A nationwide cohort study in Japan for the PRCA Collaborative Study Group. Haematologica 2007 Aug;92(8):1021-1028.

18. Dickerman JD. Transient erythroblastopenia of childhood presenting with reticulocytosis and erythroid hyperplasia in the bone marrow. Pediatrics 1981 Apr;67(4):562-564.

19. Burkhardt R, Frisch B, Bartl R. Bone biopsy in haematological disorders. J. Clin. Pathol. 1982 Mar;35(3):257-284.

20. Foot AB, Potter MN, Ropner JE, Wallington TB, Oakhill A. Transient erythroblastopenia of childhood with CD10, TdT, and cytoplasmic mu lymphocyte positivity in bone marrow. J. Clin. Pathol. 1990 Oct;43(10):857-859.

21. Carpenter SL, Zimmerman SA, Ware RE. Acute parvovirus B19 infection mimicking congenital dyserythropoietic anemia. J. Pediatr. Hematol. Oncol. 2004 Feb;26(2):133135.

22. Sheftel AD, Richardson DR, Prchal J, Ponka P. Mitochondrial iron metabolism and sideroblastic anemia. Acta Haematol. 2009;122(2-3):120-133.

23. Gregg XT, Reddy V, Prchal JT. Copper deficiency masquerading as myelodysplastic syndrome. Blood 2002 Aug 15;100(4):1493-1495.

24. Halfdanarson TR, Kumar N, Li CY, Phyliky RL, Hogan WJ. Hematological manifestations of copper deficiency: a retrospective review. Eur. J. Haematol. 2008 Jun;80(6):523-531.

25. Wickramasinghe SN, Wood WG. Advances in the understanding of the congenital dyserythropoietic anaemias. Br. J. Haematol. 2005 Nov;131(4):431-446.

26. Wickramasinghe SN. Dyserythropoiesis and congenital dyserythropoietic anaemias. Br. J. Haematol. 1997 Sep;98(4):785-797.

27. Iolascon A, De MD, Perrotta S, Carella M, Gasparini P, Lambertenghi DG. Genetic heterogeneity of congenital dyserythropoietic anemia type II. Blood 1998 Oct 1;92(7):2593-2594.

28. Holla RG, Mishra DK, Prasad AN. Congenital dyserythropoietic anemia type I. Indian J. Pediatr. 2009 Dec 11. 
29. Van DA, Broeckaert-van O, Desmet V, Verwilghen RL. Gaucher-like cells and congenital dyserythropoietic anaemia, type II (HEMPAS). Br. J. Haematol. 1973 Aug;25(2):165-170.

30. Block M. Histopathologic studies in beta-thalassemia minor and intermedia. Ann. N. Y. Acad. Sci. 1969 Nov 20;165(1):126-147.

31. Sharma P, Khurana N, Singh T. Pseudo-Gaucher cells in Hb E disease and thalassemia intermedia. Hematology. 2007 Oct;12(5):457-459.

32. Zaino EC, Rossi MB, Pham TD, Azar HA. Gaucher's cells in thalassemia. Blood 1971 Oct;38(4):457-462.

33. Miyata T, Takeda J, Iida Y, et al. The cloning of PIG-A, a component in the early step of GPI-anchor biosynthesis. Science 1993 Feb 26;259(5099):1318-1320.

34. Socie G, Mary JY, de GA, et al. Paroxysmal nocturnal haemoglobinuria: long-term follow-up and prognostic factors. French Society of Haematology. Lancet 1996 Aug 31;348(9027):573-577.

35. Wanachiwanawin W, Siripanyaphinyo U, Piyawattanasakul N, Kinoshita T. A cohort study of the nature of paroxysmal nocturnal hemoglobinuria clones and PIG-A mutations in patients with aplastic anemia. Eur. J. Haematol. 2006 Jun;76(6):502-509.

36. Perlman MK, Schwab JG, Nachman JB, Rubin CM. Thrombocytopenia in children with severe iron deficiency. J. Pediatr. Hematol. Oncol. 2002 Jun;24(5):380-384.

37. Kuku I, Kaya E, Yologlu S, Gokdeniz R, Baydin A. Platelet counts in adults with iron deficiency anemia. Platelets. 2009 Sep;20(6):401-405.

38. Finberg KE, Heeney MM, Campagna DR, et al. Mutations in TMPRSS6 cause ironrefractory iron deficiency anemia (IRIDA). Nat. Genet. 2008 May;40(5):569-571.

39. Guillem F, Lawson S, Kannengiesser C, Westerman M, Beaumont C, Grandchamp B. Two nonsense mutations in the TMPRSS6 gene in a patient with microcytic anemia and iron deficiency. Blood 2008 Sep 1;112(5):2089-2091.

40. Melis MA, Cau M, Congiu R, et al. A mutation in the TMPRSS6 gene, encoding a transmembrane serine protease that suppresses hepcidin production, in familial iron deficiency anemia refractory to oral iron. Haematologica 2008 Oct;93(10):1473-1479.

41. Hill RS, Pettit JE, Tattersall MH, Kiley N, Lewis SM. Iron deficiency and dyserythropoiesis. Br. J. Haematol. 1972 Oct;23(4):507-512.

42. Weiss G, Goodnough LT. Anemia of chronic disease. N. Engl. J. Med. 2005 Mar 10;352(10):1011-1023.

43. Voulgarelis M, Kokori SI, Ioannidis JP, Tzioufas AG, Kyriaki D, Moutsopoulos HM. Anaemia in systemic lupus erythematosus: aetiological profile and the role of erythropoietin. Ann. Rheum. Dis. 2000 Mar;59(3):217-222. 
44. Mavragani CP, Vlachaki E, Voulgarelis M. Pure red cell aplasia in a Sjogren's syndrome/lupus erythematosus overlap patient. Am. J. Hematol. 2003 Apr;72(4):259262.

45. Hara A, Wada T, Kitajima S, et al. Combined pure red cell aplasia and autoimmune hemolytic anemia in systemic lupus erythematosus with anti-erythropoietin autoantibodies. Am. J. Hematol. 2008 Sep;83(9):750-752.

46. Das PK, Wherrett D, Dror Y. Remission of aplastic anemia induced by treatment for Graves disease in a pediatric patient. Pediatr. Blood Cancer 2007 Aug;49(2):210-212.

47. Fukaya S, Yasuda S, Hashimoto T, et al. Clinical features of haemophagocytic syndrome in patients with systemic autoimmune diseases: analysis of 30 cases. Rheumatology. (Oxford) 2008 Nov;47(11):1686-1691.

48. Bass RD, Pullarkat V, Feinstein DI, Kaul A, Winberg CD, Brynes RK. Pathology of autoimmune myelofibrosis. A report of three cases and a review of the literature. Am. J. Clin. Pathol. 2001 Aug;116(2):211-216.

49. Munoz M, Villar I, Garcia-Erce JA. An update on iron physiology. World J. Gastroenterol. 2009 Oct 7;15(37):4617-4626.

50. Nemeth E, Valore EV, Territo M, Schiller G, Lichtenstein A, Ganz T. Hepcidin, a putative mediator of anemia of inflammation, is a type II acute-phase protein. Blood 2003 Apr 1;101(7):2461-2463.

51. Nemeth E, Rivera S, Gabayan V, et al. IL-6 mediates hypoferremia of inflammation by inducing the synthesis of the iron regulatory hormone hepcidin. J. Clin. Invest 2004 May;113(9):1271-1276.

52. Voulgarelis M, Giannouli S, Tasidou A, Anagnostou D, Ziakas PD, Tzioufas AG. Bone marrow histological findings in systemic lupus erythematosus with hematologic abnormalities: a clinicopathological study. Am. J. Hematol. 2006 Aug;81(8):590-597.

53. Yetgin S, Ozen S, Saatci U, Bakkaloglu A, Besbas N, Kirel B. Myelodysplastic features in juvenile rheumatoid arthritis. Am. J. Hematol. 1997 Feb;54(2):166-169.

54. Kirel B, Yetgin S, Saatci U, Ozen S, Bakkaloglu A, Besbas N. Anaemia in juvenile chronic arthritis. Clin. Rheumatol. 1996 May;15(3):236-241.

55. Oka Y, Kameoka J, Hirabayashi Y, et al. Reversible bone marrow dysplasia in patients with systemic lupus erythematosus. Intern. Med. 2008;47(8):737-742.

56. Lee J, Chang JE, Cho YJ, Han WS. A case of reactive plasmacytosis mimicking multiple myeloma in a patient with primary Sjogren's syndrome. J. Korean Med. Sci. 2005 Jun;20(3):506-508.

57. Tanvetyanon T, Leighton JC. Severe anemia and marrow plasmacytosis as presentation of Sjogren's syndrome. Am. J. Hematol. 2002 Mar;69(3):233.

58. Wickramasinghe SN. Diagnosis of megaloblastic anaemias. Blood Rev. 2006 Nov;20(6):299-318. 
59. Boxer L, Dale DC. Neutropenia: causes and consequences. Semin. Hematol. 2002 Apr;39(2):75-81.

60. Dale DC, Bolyard AA, Schwinzer BG, et al. The Severe Chronic Neutropenia International Registry: 10-Year Follow-up Report. Support. Cancer Ther. 2006 Jul $1 ; 3(4): 220-231$.

61. Aggett PJ, Cavanagh NP, Matthew DJ, Pincott JR, Sutcliffe J, Harries JT. Shwachman's syndrome. A review of 21 cases. Arch. Dis. Child 1980 May;55(5):331347.

62. Dror Y, Durie P, Ginzberg H, et al. Clonal evolution in marrows of patients with Shwachman-Diamond syndrome: a prospective 5-year follow-up study. Exp. Hematol. $2002 \mathrm{Jul} ; 30(7): 659-669$.

63. Ginzberg H, Shin J, Ellis L, et al. Shwachman syndrome: phenotypic manifestations of sibling sets and isolated cases in a large patient cohort are similar. J. Pediatr. 1999 Jul;135(1):81-88.

64. Mack DR, Forstner GG, Wilschanski M, Freedman MH, Durie PR. Shwachman syndrome: exocrine pancreatic dysfunction and variable phenotypic expression. Gastroenterology 1996 Dec;111(6):1593-1602.

65. Smith OP, Hann IM, Chessells JM, Reeves BR, Milla P. Haematological abnormalities in Shwachman-Diamond syndrome. Br. J. Haematol. 1996 Aug;94(2):279-284.

66. Boocock GR, Morrison JA, Popovic M, et al. Mutations in SBDS are associated with Shwachman-Diamond syndrome. Nat. Genet. 2003 Jan;33(1):97-101.

67. Maserati E, Pressato B, Valli R, et al. The route to development of myelodysplastic syndrome/acute myeloid leukaemia in Shwachman-Diamond syndrome: the role of ageing, karyotype instability, and acquired chromosome anomalies. Br. J. Haematol. 2009 Apr;145(2):190-197.

68. Toiviainen-Salo S, Mayranpaa MK, Durie PR, et al. Shwachman-Diamond syndrome is associated with low-turnover osteoporosis. Bone 2007 Dec;41(6):965-972.

69. Kostmann R. Infantile genetic agranulocytosis; agranulocytosis infantilis hereditaria. Acta Paediatr. Suppl 1956 Feb;45(Suppl 105):1-78.

70. Horwitz MS, Duan Z, Korkmaz B, Lee HH, Mealiffe ME, Salipante SJ. Neutrophil elastase in cyclic and severe congenital neutropenia. Blood 2007 Mar 1;109(5):18171824.

71. Dale DC, Person RE, Bolyard AA, et al. Mutations in the gene encoding neutrophil elastase in congenital and cyclic neutropenia. Blood 2000 Oct 1;96(7):2317-2322.

72. Klein C, Grudzien M, Appaswamy G, et al. HAX1 deficiency causes autosomal recessive severe congenital neutropenia (Kostmann disease). Nat. Genet. 2007 Jan;39(1):86-92. 
73. Skokowa J, Germeshausen M, Zeidler C, Welte K. Severe congenital neutropenia: inheritance and pathophysiology. Curr. Opin. Hematol. 2007 Jan;14(1):22-28.

74. Hasle H, Niemeyer CM, Chessells JM, et al. A pediatric approach to the WHO classification of myelodysplastic and myeloproliferative diseases. Leukemia 2003 Feb;17(2):277-282.

75. Rosenberg PS, Alter BP, Bolyard AA, et al. The incidence of leukemia and mortality from sepsis in patients with severe congenital neutropenia receiving long-term G-CSF therapy. Blood 2006 Jun 15;107(12):4628-4635.

76. Boztug K, Appaswamy G, Ashikov A, et al. A syndrome with congenital neutropenia and mutations in G6PC3. N. Engl. J. Med. 2009 Jan 1;360(1):32-43.

77. Haurie C, Dale DC, Mackey MC. Cyclical neutropenia and other periodic hematological disorders: a review of mechanisms and mathematical models. Blood 1998 Oct 15;92(8):2629-2640.

78. Horwitz M, Benson KF, Person RE, Aprikyan AG, Dale DC. Mutations in ELA2, encoding neutrophil elastase, define a 21-day biological clock in cyclic haematopoiesis. Nat. Genet. 1999 Dec;23(4):433-436.

79. Dale DC, Cottle TE, Fier CJ, et al. Severe chronic neutropenia: treatment and followup of patients in the Severe Chronic Neutropenia International Registry. Am. J. Hematol. 2003 Feb;72(2):82-93.

80. Donadieu J, Leblanc T, Bader MB, et al. Analysis of risk factors for myelodysplasias, leukemias and death from infection among patients with congenital neutropenia. Experience of the French Severe Chronic Neutropenia Study Group. Haematologica 2005 Jan;90(1):45-53.

81. Freedman MH, Bonilla MA, Fier C, et al. Myelodysplasia syndrome and acute myeloid leukemia in patients with congenital neutropenia receiving G-CSF therapy. Blood 2000 Jul 15;96(2):429-436.

82. Birgens HS, Karle H. Reversible adult-onset cyclic haematopoiesis with a cycle length of 100 days. Br. J. Haematol. 1993 Feb;83(2):181-186.

83. Quesenberry PJ. Cyclic hematopoiesis: disorders of primitive hematopoietic stem cells. Exp. Hematol. 1983 Sep;11(8):687-700.

84. Laporte F, Hamdi S, Oksman F, Huguet F. Auto-immune neutropenia associated with metformin in a patient with splenic marginal zone lymphoma. Pharm. World Sci. 2008 Aug;30(4):319-321.

85. Papadaki HA, Michelakaki H, Bux J, Eliopoulos GD. Severe autoimmune neutropenia associated with bone marrow sea-blue histiocytosis. Br. J. Haematol. 2002 Sep;118(4):931.

86. Shimizu H, Sawada K, Katano N, Sasaki K, Kawai S, Fujimoto T. Intramedullary neutrophil phagocytosis by histiocytes in autoimmune neutropenia of infancy. Acta Haematol. 1990;84(4):201-203. 
87. Akhtari M, Waller EK, Jaye DL, et al. Neutropenia in a patient treated with ipilimumab (anti-CTLA-4 antibody). J. Immunother. 2009 Apr;32(3):322-324.

88. Papadaki HA, Eliopoulos AG, Kosteas T, et al. Impaired granulocytopoiesis in patients with chronic idiopathic neutropenia is associated with increased apoptosis of bone marrow myeloid progenitor cells. Blood 2003 Apr 1;101(7):2591-2600.

89. Papadaki HA, Chatzivassili A, Stefanaki K, Koumaki V, Kanavaros P, Eliopoulos GD. Morphologically defined myeloid cell compartments, lymphocyte subpopulations, and histological findings of bone marrow in patients with nonimmune chronic idiopathic neutropenia of adults. Ann. Hematol. 2000 Oct;79(10):563-570.

90. Ballmaier M, Germeshausen M, Schulze H, et al. c-mpl mutations are the cause of congenital amegakaryocytic thrombocytopenia. Blood 2001 Jan 1;97(1):139-146.

91. Ballmaier M, Germeshausen M, Krukemeier S, Welte K. Thrombopoietin is essential for the maintenance of normal hematopoiesis in humans: development of aplastic anemia in patients with congenital amegakaryocytic thrombocytopenia. Ann. N. Y. Acad. Sci. 2003 May;996:17-25.

92. Ballmaier M, Germeshausen M. Advances in the understanding of congenital amegakaryocytic thrombocytopenia. Br. J. Haematol. 2009 Jun;146(1):3-16.

93. Rose MJ, Nicol KK, Skeens MA, Gross TG, Kerlin BA. Congenital amegakaryocytic thrombocytopenia: the diagnostic importance of combining pathology with molecular genetics. Pediatr. Blood Cancer 2008 Jun;50(6):1263-1265.

94. Hall JG, Levin J, Kuhn JP, Ottenheimer EJ, van Berkum KA, McKusick VA. Thrombocytopenia with absent radius (TAR). Medicine (Baltimore) 1969 Nov;48(6):411-439.

95. Bonsi L, Marchionni C, Alviano F, et al. Thrombocytopenia with absent radii (TAR) syndrome: from hemopoietic progenitor to mesenchymal stromal cell disease? Exp. Hematol. 2009 Jan;37(1):1-7.

96. Hedberg VA, Lipton JM. Thrombocytopenia with absent radii. A review of 100 cases. Am. J. Pediatr. Hematol. Oncol. 1988;10(1):51-64.

97. Cines DB, Blanchette VS. Immune thrombocytopenic purpura. N. Engl. J. Med. 2002 Mar 28;346(13):995-1008.

98. Jubelirer SJ, Harpold R. The role of the bone marrow examination in the diagnosis of immune thrombocytopenic purpura: case series and literature review. Clin. Appl. Thromb. Hemost. 2002 Jan;8(1):73-76.

99. Muhury M, Mathai AM, Rai S, Naik R, Pai MR, Sinha R. Megakaryocytic alterations in thrombocytopenia: a bone marrow aspiration study. Indian J. Pathol. Microbiol. 2009 Oct;52(4):490-494.

100. Kuter DJ, Mufti GJ, Bain BJ, Hasserjian RP, Davis W, Rutstein M. Evaluation of bone marrow reticulin formation in chronic immune thrombocytopenia patients treated with romiplostim. Blood 2009 Oct 29;114(18):3748-3756. 
101. Hoffman R, Bruno E, Elwell J, et al. Acquired amegakaryocytic thrombocytopenic purpura: a syndrome of diverse etiologies. Blood 1982 Nov;60(5):1173-1178.

102. Zent CS, Ratajczak J, Ratajczak MZ, Anastasi J, Hoffman PC, Gewirtz AM. Relationship between megakaryocyte mass and serum thrombopoietin levels as revealed by a case of cyclic amegakaryocytic thrombocytopenic purpura. $\mathrm{Br}$. $J$. Haematol. 1999 May;105(2):452-458.

103. Levitus M, Rooimans MA, Steltenpool J, et al. Heterogeneity in Fanconi anemia: evidence for 2 new genetic subtypes. Blood 2004 Apr 1;103(7):2498-2503.

104. Dorsman JC, Levitus M, Rockx D, et al. Identification of the Fanconi anemia complementation group I gene, FANCI. Cell Oncol. 2007;29(3):211-218.

105. Dokal I, Vulliamy T. Inherited aplastic anaemias/bone marrow failure syndromes. Blood Rev. 2008 May;22(3):141-153.

106. Giampietro PF, Verlander PC, Davis JG, Auerbach AD. Diagnosis of Fanconi anemia in patients without congenital malformations: an international Fanconi Anemia Registry Study. Am. J. Med. Genet. 1997 Jan 10;68(1):58-61.

107. Kutler DI, Singh B, Satagopan J, et al. A 20-year perspective on the International Fanconi Anemia Registry (IFAR). Blood 2003 Feb 15;101(4):1249-1256.

108. Cioc AM, Wagner JE, MacMillan ML, DeFor T, Hirsch B. Diagnosis of myelodysplastic syndrome among a cohort of 119 patients with fanconi anemia: morphologic and cytogenetic characteristics. Am. J. Clin. Pathol. 2010 Jan;133(1):92100.

109. Alter BP. Diagnosis, genetics, and management of inherited bone marrow failure syndromes. Hematology. Am. Soc. Hematol. Educ. Program. 2007;29-39.

110. Jacobs P, Karabus C. Fanconi's anemia. A family study with 20-year follow-up including associated breast pathology. Cancer 1984 Nov 1;54(9):1850-1853.

111. Zhu AX, D'Andrea AD, Sahani DV, Hasserjian RP. Case records of the Massachusetts General Hospital. Case 13-2006. A 50-year-old man with a painful bone mass and lesions in the liver. N. Engl. J. Med. 2006 Apr 27;354(17):1828-1837.

112. Knight S, Vulliamy T, Copplestone A, Gluckman E, Mason P, Dokal I. Dyskeratosis Congenita (DC) Registry: identification of new features of DC. Br. J. Haematol. 1998 Dec;103(4):990-996.

113. Calado RT, Young NS. Telomere maintenance and human bone marrow failure. Blood 2008 May 1;111(9):4446-4455.

114. Calado RT, Young NS. Telomere diseases. N. Engl. J. Med. 2009 Dec 10;361(24):2353-2365.

115. Brodsky RA, Jones RJ. Aplastic anaemia. Lancet 2005 May 7;365(9471):1647-1656. 
116. Tichelli A, Gratwohl A, Nissen C, Signer E, Stebler GC, Speck B. Morphology in patients with severe aplastic anemia treated with antilymphocyte globulin. Blood 1992 Jul 15;80(2):337-345.

117. Rosenfeld S, Follmann D, Nunez O, Young NS. Antithymocyte globulin and cyclosporine for severe aplastic anemia: association between hematologic response and long-term outcome. JAMA 2003 Mar 5;289(9):1130-1135.

118. Maciejewski JP, Risitano A, Sloand EM, Nunez O, Young NS. Distinct clinical outcomes for cytogenetic abnormalities evolving from aplastic anemia. Blood 2002 May 1;99(9):3129-3135.

119. de Planque MM, Bacigalupo A, Wursch A, et al. Long-term follow-up of severe aplastic anaemia patients treated with antithymocyte globulin. Severe Aplastic Anaemia Working Party of the European Cooperative Group for Bone Marrow Transplantation (EBMT). Br. J. Haematol. 1989 Sep;73(1):121-126.

120. Milosevic R, Jankovic G, Antonijevic N, Jovanovic V, Babic D, Colovic M. [Histopathologic characteristics of bone marrow in patients with aplastic anemia (abstract)]. Srp. Arh. Celok. Lek. 2000 May;128(5-6):200-204.

121. Te VJ, Haak HL. Aplastic anaemia. Histological investigation of methacrylate embedded bone marrow biopsy specimens; correlation with survival after conventional treatment in 15 adult patients. Br. J. Haematol. 1977 Jan;35(1):61-69.

122. Baumann I, Niemeyer CM, Bennet JM, Shannon K. Childhood myelodysplastic syndrome. In Swerdlow S, Campo E, Lee Harris N, et al., eds. WHO Classification of Tumours of Haematopoietic and Lymphoid Tissues. 4th ed. Lyon: WHO Press; 2010. 104-107.

123. Lorand-Metze I, Meira DG, Lima CS, Vassallo J, Metze K. The differential diagnosis between aplastic anemia and hypocellular myelodysplasia in patients with pancytopenia. Haematologica 1999 Jun;84(6):564-565.

124. Fohlmeister I, Fischer R, Modder B, Rister M, Schaefer HE. Aplastic anaemia and the hypocellular myelodysplastic syndrome: histomorphological, diagnostic, and prognostic features. J. Clin. Pathol. 1985 Nov;38(11):1218-1224.

125. Orazi A, Albitar M, Heerema NA, Haskins S, Neiman RS. Hypoplastic myelodysplastic syndromes can be distinguished from acquired aplastic anemia by CD34 and PCNA immunostaining of bone marrow biopsy specimens. Am. J. Clin. Pathol. 1997 Mar;107(3):268-274.

126. Matsui WH, Brodsky RA, Smith BD, Borowitz MJ, Jones RJ. Quantitative analysis of bone marrow CD34 cells in aplastic anemia and hypoplastic myelodysplastic syndromes. Leukemia 2006 Mar;20(3):458-462.

127. Hasle H, Wadsworth LD, Massing BG, McBride M, Schultz KR. A population-based study of childhood myelodysplastic syndrome in British Columbia, Canada. Br. J. Haematol. 1999 Sep;106(4):1027-1032. 
128. Passmore SJ, Chessells JM, Kempski H, Hann IM, Brownbill PA, Stiller CA. Paediatric myelodysplastic syndromes and juvenile myelomonocytic leukaemia in the UK: a population-based study of incidence and survival. Br. J. Haematol. 2003 Jun;121(5):758-767.

129. Kardos G, Baumann I, Passmore SJ, et al. Refractory anemia in childhood: a retrospective analysis of 67 patients with particular reference to monosomy 7. Blood 2003 Sep 15;102(6):1997-2003.

130. Brunning R, Orazi A, Germing U, et al. Myelodysplastic syndromes/neoplasms, overview. In Swerdlow S, Campo E, Lee Harris N, et al., eds. WHO classification of tumours of haematopoietic and lymphoid tissues. 4th ed. Lyon: WHO Press; 2010. 75.

131. Stary J, Baumann I, Creutzig U, Harbott J, Michalova K, Niemeyer C. Getting the numbers straight in pediatric MDS: distribution of subtypes after exclusion of down syndrome. Pediatr. Blood Cancer 2008 Feb;50(2):435-436.

132. Polychronopoulou S, Panagiotou JP, Kossiva L, Mavrou A, Anagnostou D, Haidas S. Clinical and morphological features of paediatric myelodysplastic syndromes: a review of 34 cases. Acta Paediatr. 2004 Aug;93(8):1015-1023.

133. Orazi A. Histopathology in the diagnosis and classification of acute myeloid leukemia, myelodysplastic syndromes, and myelodysplastic/myeloproliferative diseases.

Pathobiology 2007;74(2):97-114.

134. Zhao X, Sun NC, Witt MD, Keller M, Niihara Y. Changing pattern of AIDS: a bone marrow study. Am. J. Clin. Pathol. 2004 Mar;121(3):393-401.

135. Meira DG, Lorand-Metze I, Toro AD, Silva MT, Vilela MM. Bone marrow features in children with HIV infection and peripheral blood cytopenias. J. Trop. Pediatr. 2005 Apr;51(2):114-119.

136. Bain BJ. The haematological features of HIV infection. Br. J. Haematol. 1997 Oct;99(1):1-8.

137. Osborne BM, Guarda LA, Butler JJ. Bone marrow biopsies in patients with the acquired immunodeficiency syndrome. Hum. Pathol. 1984 Nov;15(11):1048-1053.

Figures: 


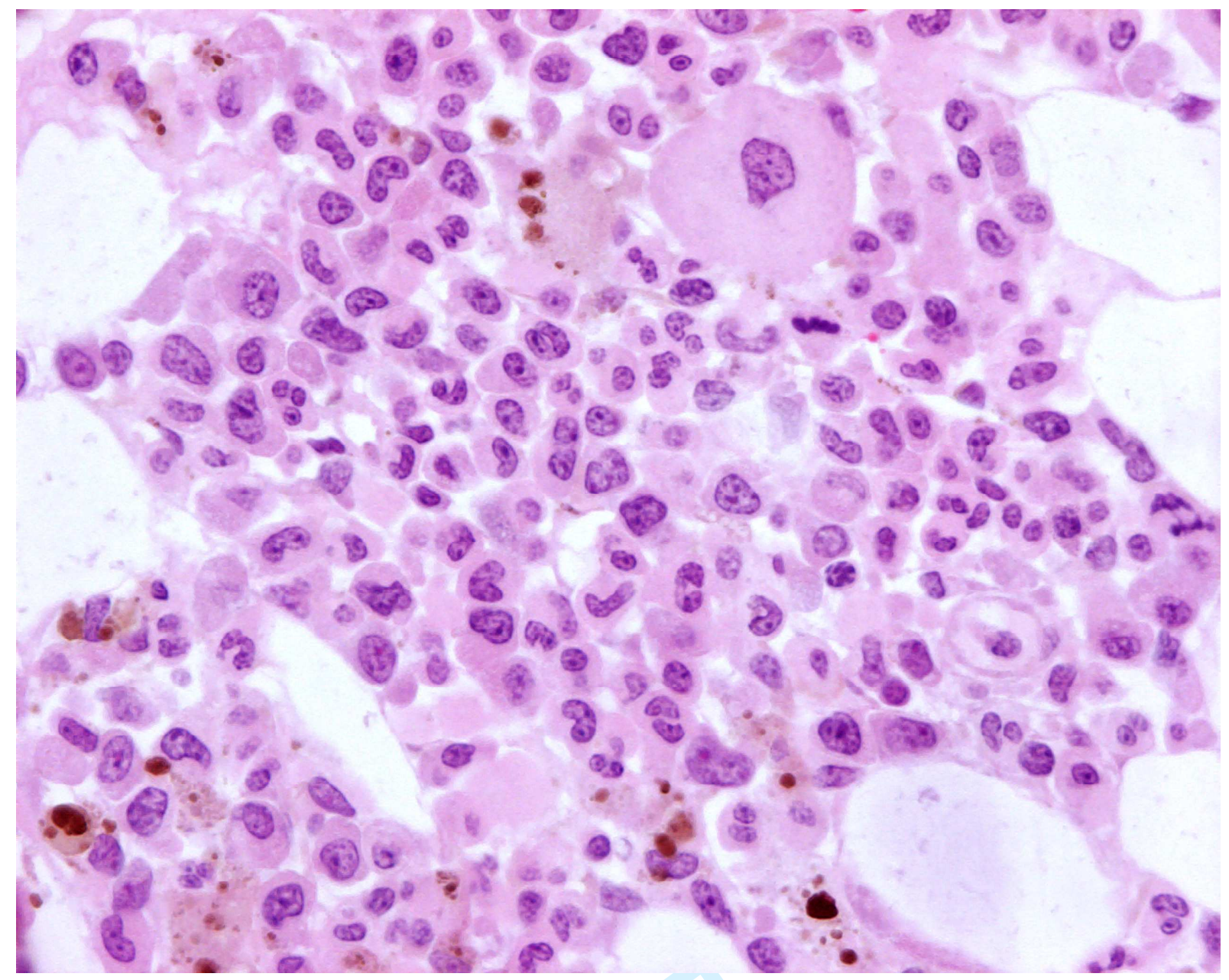

Figure 1: Pure red cell aplasia 


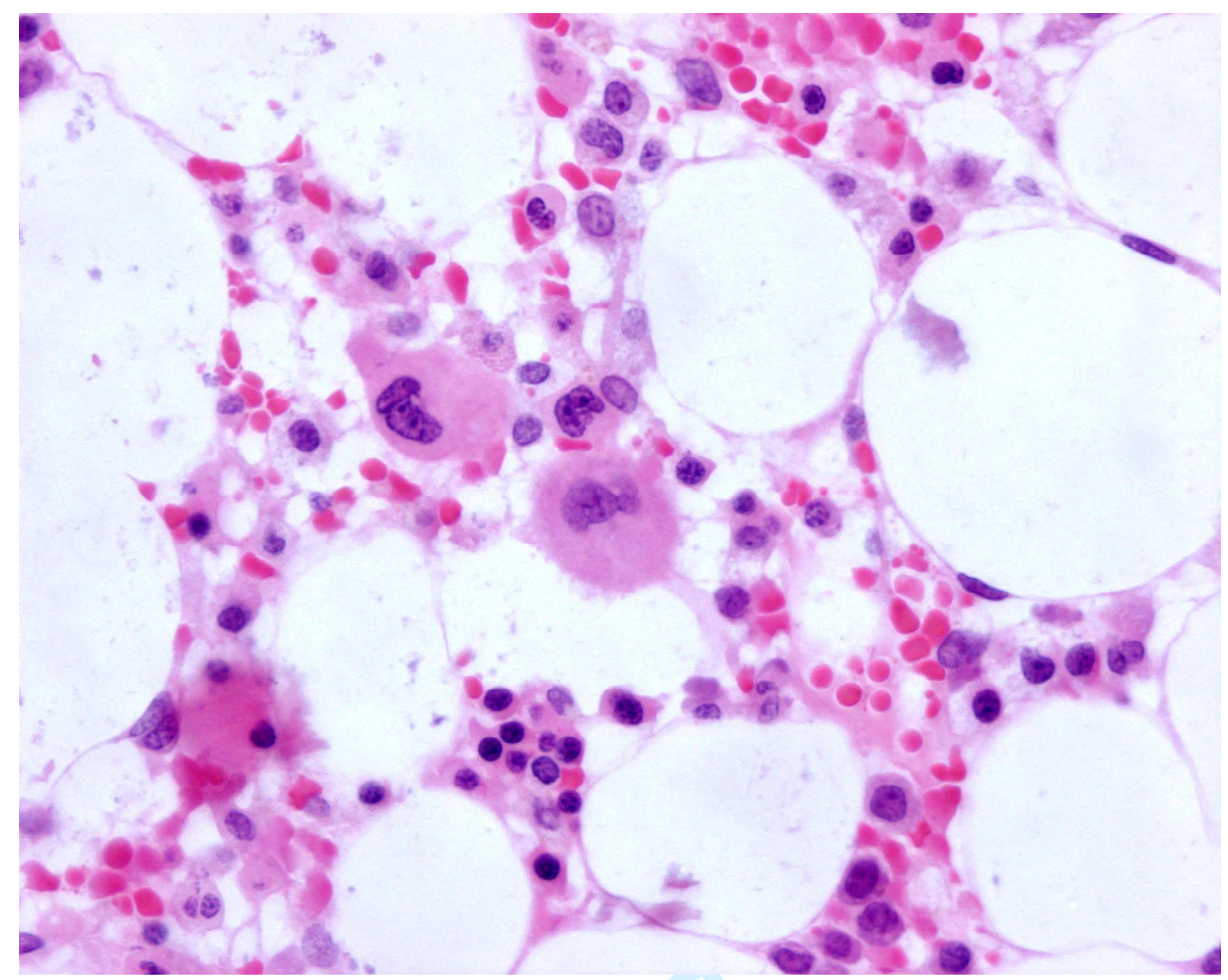

Figure 2: Shwachman-Diamond syndrome 


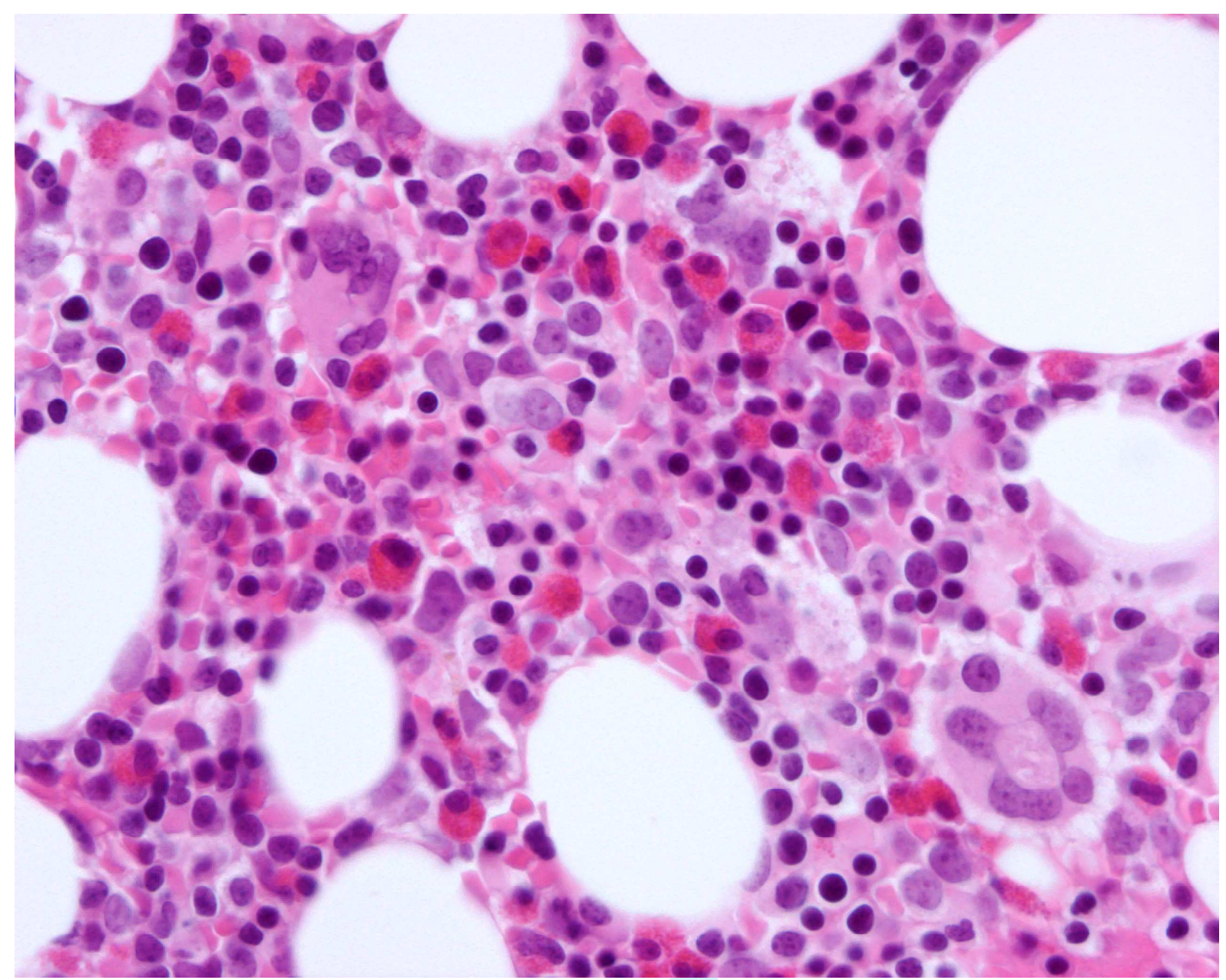

Figure 3: Severe congenital neutropenia 


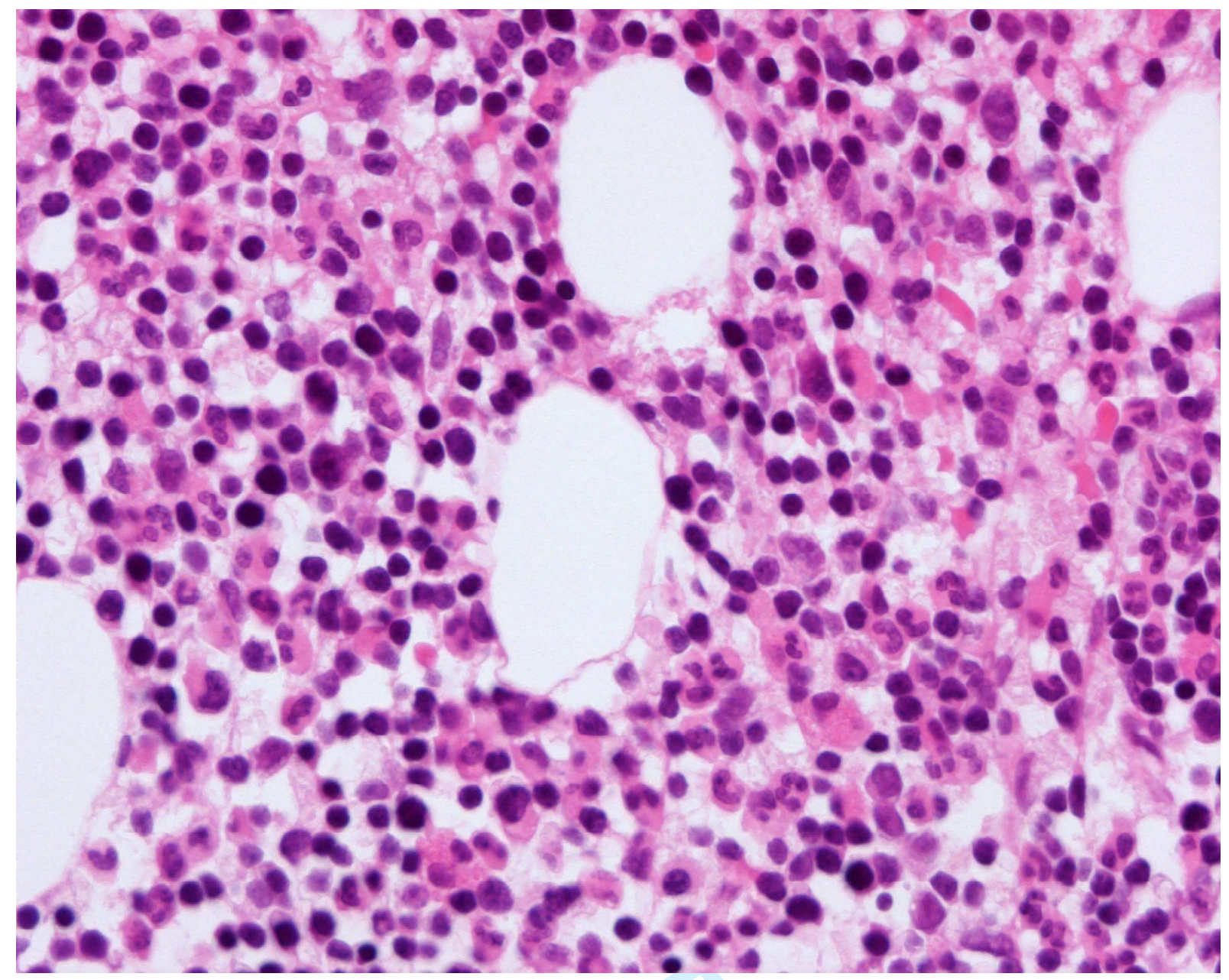

Figure 4: Congenital amegakaryocytic thrombocytopenia 


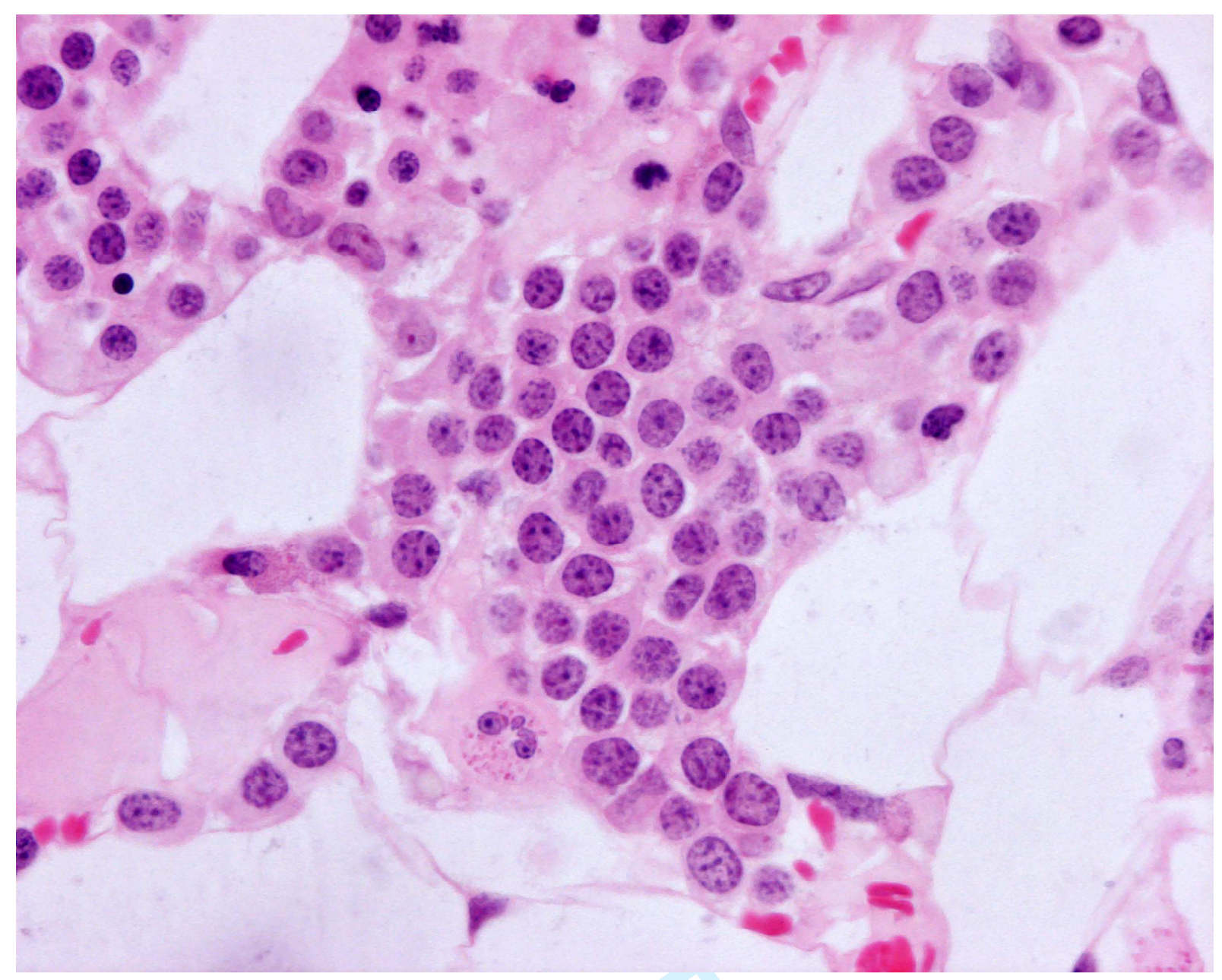

Figure 5: Fanconi anaemia 


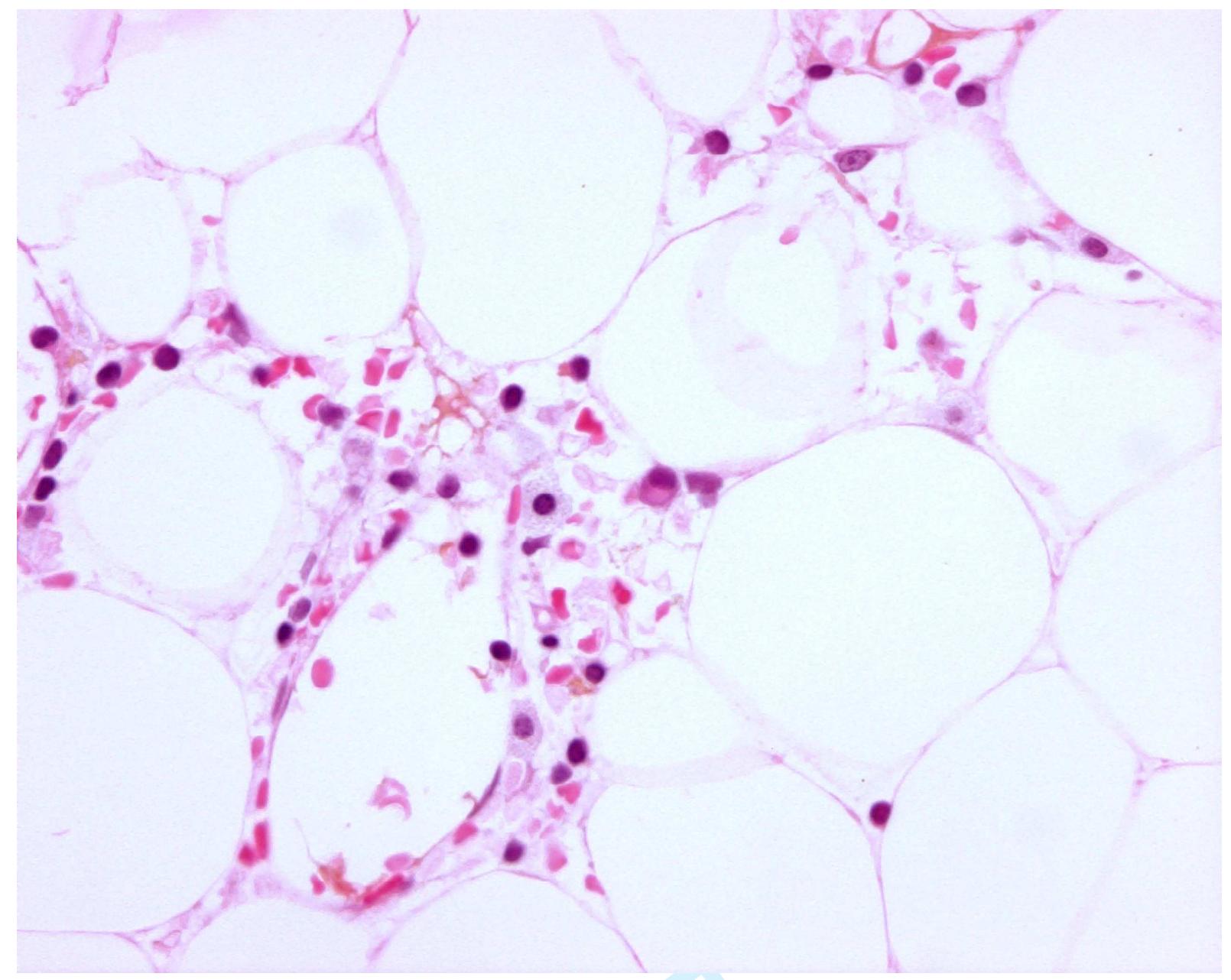

Figure 6: Aplastic anemia 


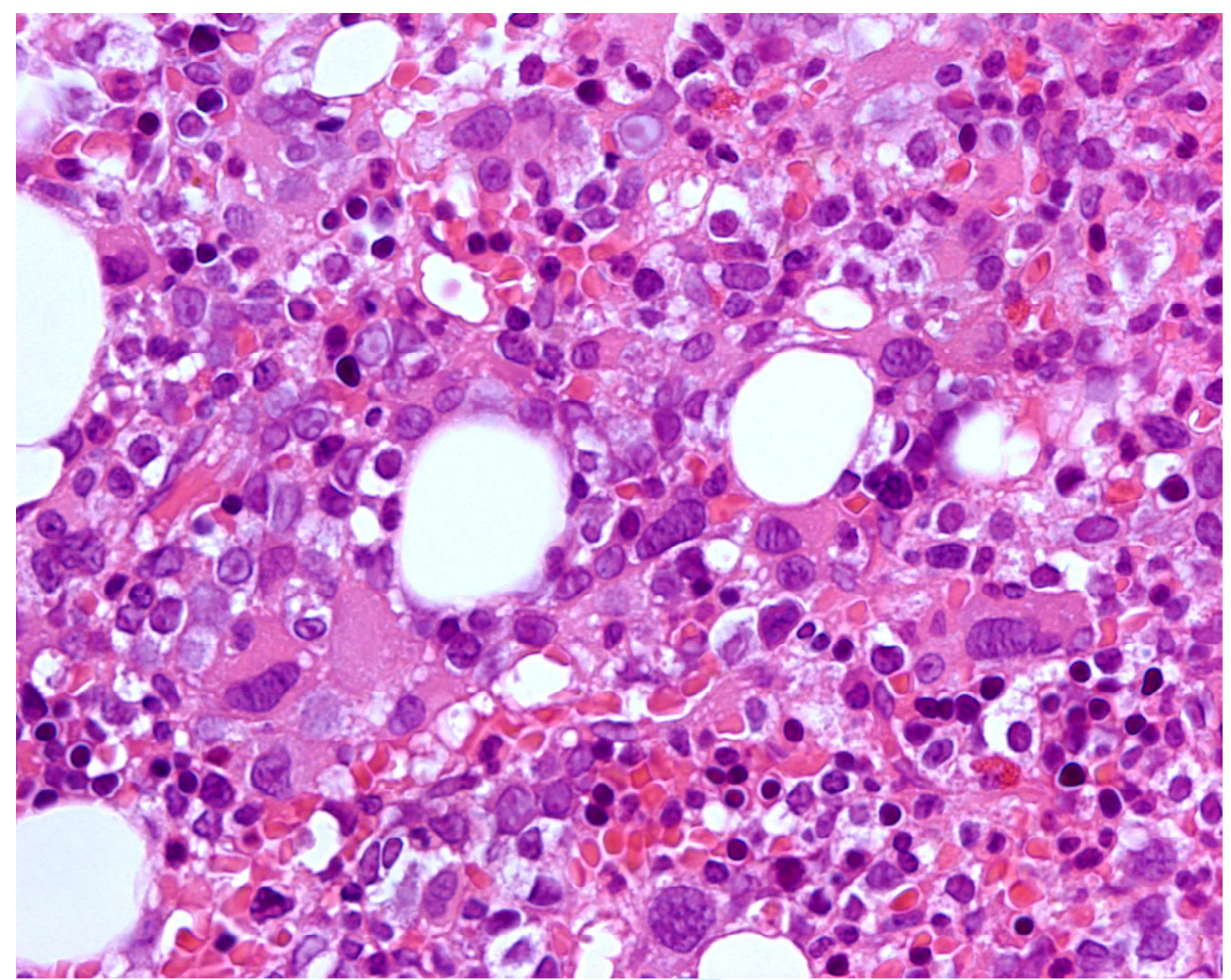

Figure 7: Myelodysplastic syndrome 
Figure legends:

Figure 1: Pure red cell aplasia in an 18 year old male with Hodgkin lymphoma in remission. The bone marrow is normocellular but consist mainly of granulopoisis and megakarypoiesis. Maturing erythropoiesis is not seen. Iron stores are increased due to blood transfusions.

Figure 2: Shwachman-Diamond syndrome. Case of an 8 year old boy with a hypocellular bone marrow, dispersed erythropoiesis and mainly immature granulocyte precursors. Megakaryocytes are present in normal numbers. This patient later developed pancytopenia.

Figure 3: Severe congenital neutropenia. Normocellular bone marrow in an 8 year old child, showing normal erythropoiesis and megakaryopoiesis. Neutrophil maturation is virtually absent. Eosinophils are increased.

Figure 4: Congenital amegakaryocytic thrombocytopenia. Normocellular marrow with maturing granulopoiesis, slightly hyperplastic erythropoiesis and absence of normal megakaryocytes.

Figure 5: Fanconi anaemia in a 4 year old boy. Hypocellular bone marrow with a focus of early erythroblasts. This dyserythropoiesis is typical of FA and should not be confused with MDS.

Figure 6: Aplastic anaemia in a 14 year old girl. Markedly hypocellular bone marrow devoid of hematopoietic cells with only scattered lymphocytes, plasma cells and mast cells.

Figure 7: Myelodysplastic syndrome in a 65 years old female. Hypercellular bone marrow with a disturbed architecture. Erythropoiesis is scattered and immature forms and nuclear irregularities are seen. There is decreased maturation of the myeloid precursors and immature myeloid precursors are abnormally located in the centre of the bone marrow fields.

Megakaryocytes are small and atypical showing hypolobulation. 